\title{
Potential new reference materials for caloric measurements on PCM
}

\author{
Harald Mehling ${ }^{1} \cdot$ Jan Leys ${ }^{2} \cdot$ Christ Glorieux $^{2} \cdot$ Jan Thoen $^{2}$
}

Received: 12 February 2020 / Accepted: 19 November 2020 / Published online: 25 January 2021

(C) The Author(s) 2021 OPEN

\begin{abstract}
Current applications of PCM focus on the temperature range from about $-40^{\circ} \mathrm{C}$ to about $+80^{\circ} \mathrm{C}$, with the interest expanding up to about $400^{\circ} \mathrm{C}$ for future applications in power plants and industry. Calorimetric measurements to determine the ability of PCM to store heat as a function of temperature are done with a variety of methods and instruments. Some of them have been developed only in the last decade, especially to allow characterization of larger samples, even encapsulated PCM with volume in the order of $100 \mathrm{ml}$ and larger. Currently there are not enough reference materials for calibration and testing available to sufficiently cover the required temperature range, being suitable for the used variety of samples regarding size, as well as other requirements of the new methods and instruments. In this paper, we give an introduction, review, and recommendations for new reference materials for calibration and testing.
\end{abstract}

Keywords PCM · Calorimetric methods · Adiabatic calorimetry $\cdot$ DSC $\cdot$ T-history $\cdot$ Reference material $\cdot$ Calibration $\cdot$ Testing

\section{Introduction}

\subsection{PCM, their fields of application, and scope of this work}

Materials that are able to store and release a considerable amount of heat while undergoing a phase change are called phase change materials (PCM). To achieve a high heat storage density at small volume and small volume change, most applied PCM undergo a phase change between solid and liquid; the phase change is then called melting and solidification. Some PCM undergo a phase change between two different solid phases. In general, it is thus a phase change on heating and on cooling.

The ability to store and release a considerable amount of heat while undergoing a phase change at small temperature changes results in two main fields of use [1]: heat storage with high storage density (per unit mass or volume) in a small temperature interval, and passive temperature stabilization. Applications focusing on storage of heat are, e.g. in buildings, industry, or power plants, and applications focusing on passive temperature stabilization are, e.g. in transport boxes, textiles, and again buildings. The temperature in current applications covers a range from about $-40^{\circ} \mathrm{C}$ to about $+80^{\circ} \mathrm{C}$, while interest for future applications in power plants and industrial applications is up to about $400^{\circ} \mathrm{C}$. Common PCM are water (ice storage), salt hydrates, salts, and eutectic salt-water solutions, as well as paraffins, fatty acids, and sugar alcohols. A PCM can be a pure material or a mixture, and it can also be inhomogeneous due to additives or phase separation. For application, the PCM is often encapsulated, with capsule sizes ranging from about $10 \mu \mathrm{m}$ (micro-encapsulation) to several $10 \mathrm{~cm}$ in cross-section (macro-encapsulation). Calorimetric measurements to determine the ability of PCM to store heat as a function of temperature are thus performed with a variety of methods and instruments. Some of them have been developed only in the last decade, especially to allow characterization of larger samples, even encapsulated PCM with volume in the order of $100 \mathrm{ml}$ and larger. In this paper, we give an introduction, review, and recommendations for new reference materials

4 Harald Mehling, harald.mehling@gmail.com $\mid{ }^{1}$ Independent Consultant, Weingartenstr. 37, 97072 Würzburg, Germany. ${ }^{2}$ Soft Matter and Biophysics, Department of Physics and Astronomy, KU Leuven, Celestijnenlaan 200D, Box 2416, 3001 Leuven, Belgium.

SN Applied Sciences (2021) 3:202 | https://doi.org/10.1007/s42452-020-03929-y 
for calibration and testing, needed to cover the full range of temperatures and sample sizes.

\subsection{Basic effects and terms}

For the following discussion, it is helpful to define some basic terms. At the center of the discussion is the capacity of a material for storage of heat as a function of temperature. For its description, the specific enthalpy $\mathrm{h}(\mathrm{T})$ and specific heat capacity $c_{p}(T)=d h(T) / d T$ are usually used.

Ideally, PCM undergo the phase change at a single phase change temperature $\mathrm{T}_{\mathrm{pc}}$. This case, ideal phase change behavior, is shown in Fig. 1. PCM are selected to have a high phase change enthalpy, better called enthalpy change during phase change $\Delta_{\mathrm{pc}} \mathrm{h}$. At an ideal single $\mathrm{T}_{\mathrm{pc}}$ the value of $c_{p}$ is infinite due to the step in $h$. The relevant data to characterize an ideal PCM are then $\mathrm{T}_{\mathrm{pc}}$ and $\Delta_{\mathrm{pc}} \mathrm{h}$; they are commonly tabulated. The enthalpy change $\Delta_{p c} h$ is also called latent heat, meaning "hidden" heat as the temperature T remains unchanged at $\mathrm{T}_{\mathrm{pc}}$ while heat is stored/ released during the phase change.

Most PCM however show non-ideal phase change behavior. There are different types of it. A type of nonideal phase change behavior is a phase change temperature range, as Fig. 2 shows.

A different behavior on heating and cooling is also possible, called hysteresis. The case of two different curves for a phase change temperature range shows Fig. 3. Another cause for hysteresis is subcooling, also called supercooling or undercooling. It is due to a metastable state: when cooling, the new phase is not formed until a sufficiently low temperature, the nucleation temperature $T_{\text {nuc }}$ is reached (Fig. 3). The effect depends e.g. on the sample size [2]; water nucleates between $0{ }^{\circ} \mathrm{C}$ in large volumes and about $-40^{\circ} \mathrm{C}$ [3] e.g. in small droplets.

The relevant data to characterize a PCM in general are thus not just, as commonly done, $T_{p c}$ and $\Delta_{\mathrm{pc}} \mathrm{h}$. An accurate way of data presentation/communication is the tabulation of the stored heat in temperature intervals for the case of heating and for the case of cooling, like $c_{p}$, or plotting the $h(T)$ curves. When using $h(T)$, normalization should be done in the liquid, close to the phase change region; if normalized in the solid, different crystallinity etc. can lead to different $\mathrm{h}$ for the same T. The effect of subcooling should be treated separately by giving the nucleation temperature $T_{\text {nuc }}$ and the measurement conditions e.g. sample size; this is because it commonly depends on the sample size and can be affected externally e.g. by the container walls, thus is not a material property.

The following discussion uses preferably $h(T)$ and not $c_{p}(T)$. The reason for this is that $h(T)$ data show not only the temperature variation, but additionally also the integral value of the heat stored directly. In addition, $c_{p}(T)$ is not useful to discuss ideal phase change as its value becomes
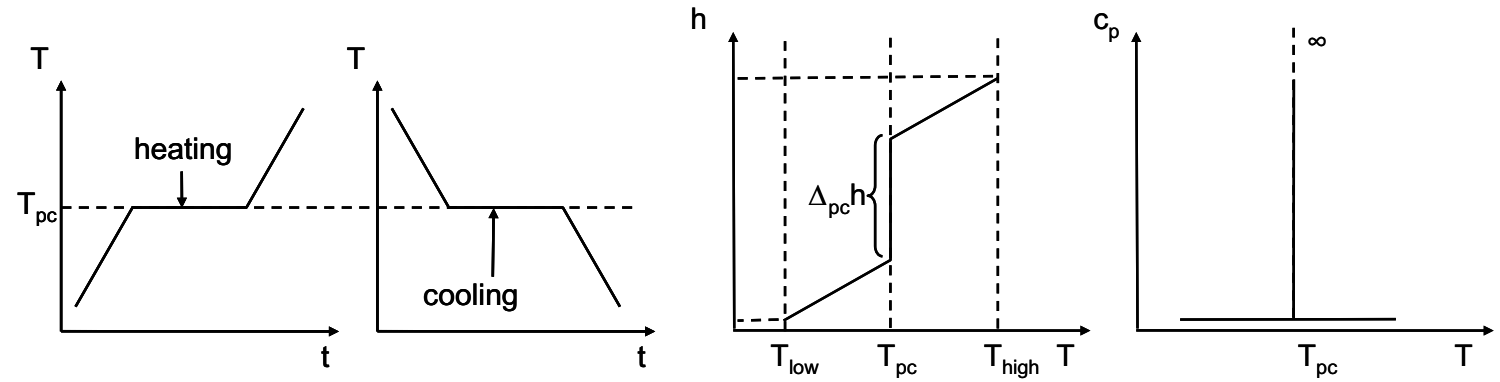

Fig. 1 Ideal phase change: heating and cooling $T(t), h(T)$, and $c_{p}(T)$
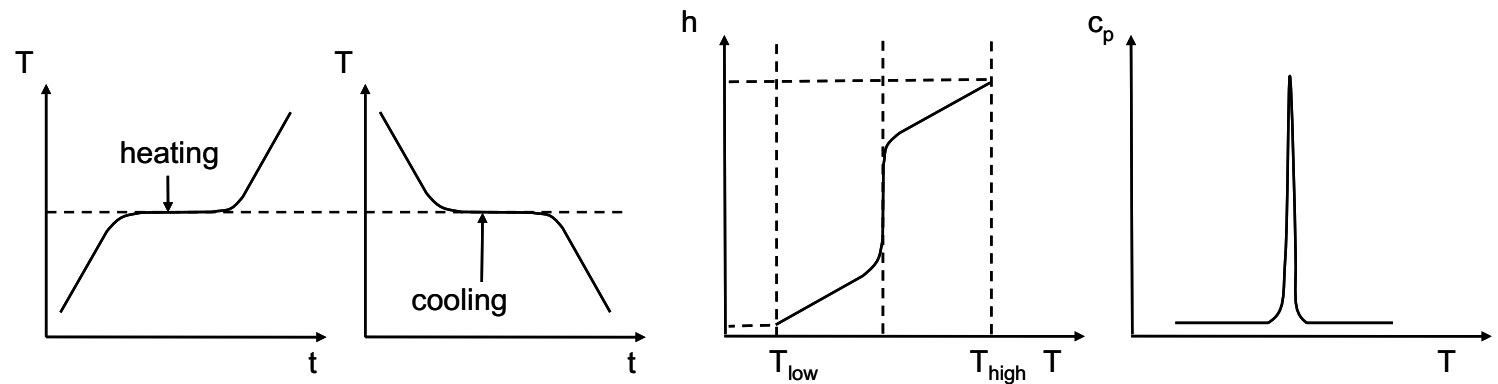

Fig. 2 Non-ideal phase change: phase change temperature range; heating and cooling $T(t), h(T)$, and $c_{p}(T)$ 

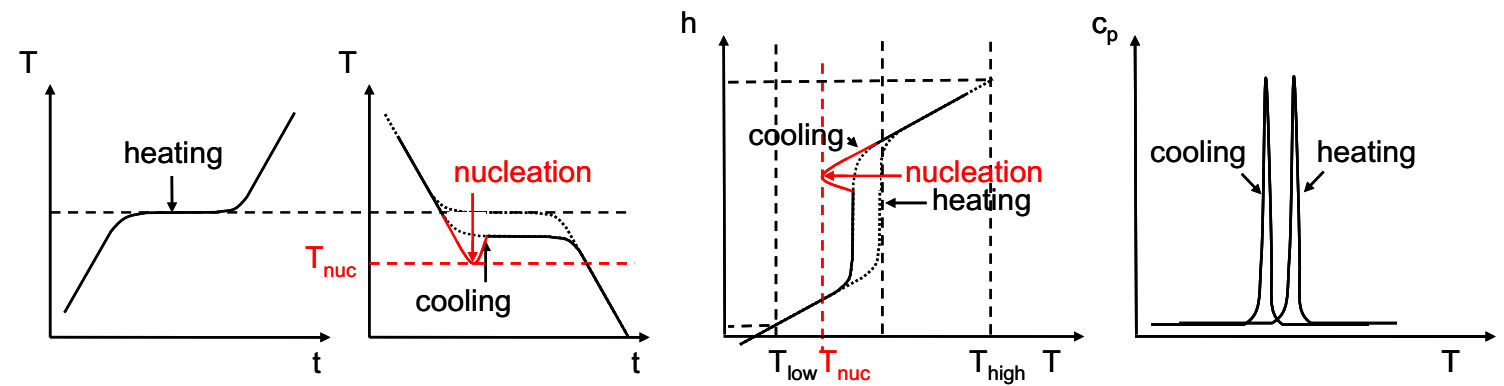

Fig. 3 Non-ideal phase change: hysteresis incl. subcooling, here with a phase change temperature range; heating and cooling $T(t), h(T)$, and $c_{p}(T)$. In $c_{p}(T)$, the effect of subcooling cannot be depicted

infinite. This is also the reason why it is common that people refer to $c_{p}$ only in the temperature range outside the phase change; the different use of the term is a frequent source of misunderstandings. Nevertheless, $c_{p}$ data are a common output of many calorimeters. Care must then be taken when integrating $c_{p}(T)$ data to $h(T)$ data in a temperature range where $c_{p}$ changes strongly while there is a low density of data points.

\section{Calorimetric methods used for PCM}

\subsection{Reference materials and their use}

The stored heat as a function of temperature, e.g. given as enthalpy change with respect to a reference temperature, is determined by calorimetric measurements. In a calorimetric measurement, the heat flow into or out of a sample is measured in connection with the sample temperature, giving also the resulting temperature change. Heat exchange and temperature are measured by sensors. The relation between the value and the signal of a sensor, thus the input and output, is called signal-value function, transfer function, or response function. Often it is not well known, or not known at all. The procedure of establishing a signal-value function is called calibration. For a calibration, one or several reference points are necessary; these are values of the property to be measured from so-called reference materials. A reference material is a material with a property that is highly constant with time and where a property value is well known. Certified reference materials have a value that has been accepted by experts by definition or from highly accurate measurements; e.g. the kilogram, the meter, the atomic unit, or the temperature fixed points e.g. in ITS-90. From the signal resulting from a measurement and the known property value of one or several reference materials the function between the value to be determined and the signal is found. For calorimetry, reference materials for temperature and amounts of heat are needed. Commonly, they refer to melting or triple point for temperature, and for heat to the related phase change enthalpy or the heat capacity of solids and liquids. Materials, and recommended values, are e.g. found in [4-6]. Figure 4 shows an overview on certified reference materials for $T_{p c} \Delta_{p c} h$, and $c_{p}$ in the temperature range from -40 to $+160{ }^{\circ} \mathrm{C}$; thus also includes the high temperatures of immediate interest in PCM R\&D.

Calibration of sensors is only one application of reference materials. Somewhat similar is their use in a relative/ comparative measurement. A relative/comparative measurement compares the sample with a reference directly during the measurement process; this allows a result relative to the reference, e.g. the measured sample value is smaller/larger than the reference value. If the signal-value function is linear, the ratio of both values and the wellknown value of the reference can be used to calculate the value of the sample. Last, but not least, reference materials are also used for testing of methods, equipment, operating personnel etc. The availability of reference materials is crucial with regard to all these usages, thus must cover not only the temperature range, but also specifics of equipment including sample size, cost, and safety etc. We will now discuss the different methods and equipment.

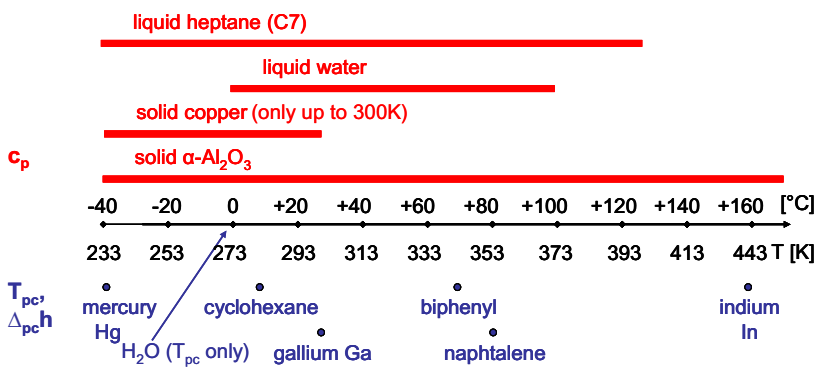

Fig. 4 Overview on certified reference materials in the temperature range from -40 to $+160^{\circ} \mathrm{C}$, above the $T$ axis for $c_{p}$, below for $T_{p c}$ and $\Delta_{\mathrm{pc}} \mathrm{h}$ 


\subsection{Individual calorimetric methods}

To discuss the need for new reference materials and the requirements on them, it is necessary to first look at the methods used for calorimetric measurements on PCM. These are hf-DSC, T-history method, 3-layer calorimeter, and AC (adiabatic calorimeter). In addition, methods to determine the thermal conductivity have been modified for calorimetric measurements; these are heat flow meter (HFM), guarded hot plate (GHP), and longitudinal guarded comparative calorimeter. They all are now discussed briefly, with a focus on what is relevant for the use and selection of reference materials.

The stored heat as a function of temperature is, at constant pressure, given as the enthalpy change with respect to a reference temperature

$\Delta Q_{p=c o n s t}=\Delta H$

or as heat capacity at constant pressure

$C_{p}(T)=\left.\frac{d Q}{d T}\right|_{p=\text { const }}=\frac{d H}{d T}$

Specific values, regarding mass or volume, are denoted by $c, q$, and $h$.

\subsubsection{Calorimetric methods with heat flow via a thermal resistance}

In a calorimetric measurement, the heat flow into or out of a sample is measured in connection with the sample temperature. The heat flow into or out of a sample can be realized in different ways. In DSC, T-history, or 3-layer calorimeter it is by a thermal resistance $R_{\text {th }}$ between sample and ambient, so

$\Delta Q_{p=\text { const }}=\Delta H=\frac{1}{R_{\text {th }}} \cdot\left(T_{s}-T_{a}\right) \cdot \Delta t$

$\left(T_{s}\right.$ and $T_{a}$ denote sample and ambient temperature, $t$ the time). This thermal resistance must be calibrated.

The most widespread commercially available calorimetric method is hf-DSC. In a heat flow Differential Scanning Calorimeter ( $h f-D S C$ ), a difference measurement is performed between a sample and a reference crucible. Both are subject to the same varying temperature in their ambient, commonly at constant heating/cooling rate $\mathrm{dT}_{\mathrm{a}} /$ $\mathrm{dt}$ (dynamic), but also stepwise is possible. The reference crucible remains empty, thus ideally the signal from the difference measurement is due to the sample without its crucible. To determine the heat flow in/out of a sample from the measured temperature difference between sample and reference crucible, the heat flow signal must be calibrated. For this, a sample from a reference material is measured. For calibration, all materials shown in Fig. 4 with melting point and enthalpy are used to calibrate sensors for temperature and heat flow. Materials with $c_{p}$ are only useful to calibrate sensors for heat flow; here $\mathrm{Al}_{2} \mathrm{O}_{3}$ is most popular, specifically at high temperatures. Hf-DSC equipment covers the temperature range from below $-50{ }^{\circ} \mathrm{C}$ to beyond $1500^{\circ} \mathrm{C}$. Typical sample size is $10-100 \mu$, thus unsuitable for PCM composites as well as PCM that subcool in such small amounts. Larger samples of $500 \mu \mathrm{l}$ or more are possible with Calvet-DSC; they can also be calibrated for heat by an electric heat source. Sample crucibles are metallic or ceramic, and metallic ones can also be sealed by cold-welding.

The T-history method is the most widespread self-built calorimetric equipment used for PCM. It is based on observing the T-history $\mathrm{T}(\mathrm{t})$ of a sample, e.g. in metallurgy where an eutectic point is indicated by a temperature plateau during cooling; thus, the method originally is purely qualitative. For PCM it was initially proposed by Zhang et al. [7] to avoid the high cost of DSC and the limitation in sample size. In the proposed method, the sample as well as a reference material are contained in test tubes, placed symmetrically in a temperature-controlled ambience, and exposed to a sudden change in temperature. During the temperature adjustment of the sample and the reference, the ambience is kept at constant temperature. From the recorded $T(t)$ of the reference, the thermal resistance of the reference to the ambient is known. Assuming that it is the same for the sample, the heat flow in or out of the sample can be calculated from its $T(t)$. Due to the variable heat transfer in air, the method was initially not very accurate. It was then modified successively, e.g. by Marín et al. [8] and Lázaro et al. [9]. The key was using insulated test tubes for the sample and the reference to increase their thermal resistance to the ambient, making the sample and reference more isothermal, and dominating overall heat transfer to assure that sample and reference have the same heat transfer resistance to the ambient. Existing equipment covers the temperature range from about $-40{ }^{\circ} \mathrm{C}$ to $200^{\circ} \mathrm{C}$, and sample size in the range of $10-20 \mathrm{ml}$, thus about 2 orders of magnitude larger than typical hf-DSC. The sample and reference containers are tubes from metal, plastic, or glass, and closed by a rubber plug or screw cap. As reference material in the measurement, water is commonly used (using its $c_{p}$ ). Rathgeber et al. [10] describe a T-History calorimeter covering up to $200{ }^{\circ} \mathrm{C}$ and, due to the wide temperature range, used copper $\left(c_{p}\right)$ as reference material in the measurement, instead of water. The calibration is refined using, besides copper $\left(c_{p}\right)$, also indium $\left(T_{p c^{\prime}}\right.$ $\left.\Delta_{\mathrm{pc}} \mathrm{h}\right)$ and $\mathrm{h}(\mathrm{T})$ data of three PCM from DSC measurements.

The 3-layer calorimeter is commercially available from just a single company, w\&a (wärme- und anwendungstechnische Prüfungen, Fürstenwalde, Germany), and 
was solely developed for PCM. The measurement principle is similar to that of the T-history method, but instead of cylindrical tubes a box-shaped sample chamber, which is insulated, is used. And there is only a single chamber, so the calibration of the thermal resistance to the ambient must be done before any PCM sample is measured. The equipment measures samples encapsulated in flat bags of $100 \mathrm{ml}$ size, thus about one order of magnitude larger than common T-history equipment, and 3 orders of magnitude larger than for common hf-DSC. The temperature range of the instrument is from $-20^{\circ} \mathrm{C}$ to $100^{\circ} \mathrm{C}$. Calibration is done by the manufacturer only, using water and hexadecane (99\%).

\subsubsection{Calorimetric methods with electric heating}

The determination of the heat flow in or out of a sample via a thermal resistance and the temperature difference between its ends (Eq. 3), as used in hf-DSC, T-history, and 3-layer calorimeter, is not the only possible measurement principle. A completely different approach to realize the heat flow, not by a thermal resistance, is by electric heating. The heating power is $\mathrm{P}_{\mathrm{el}}=\mathrm{U} \cdot \mathrm{I}$ with $\mathrm{U}$ the voltage difference and I the electric current (el.). Then

$\Delta Q_{p=\text { const }}=\Delta H=P_{e l} \cdot \Delta t=U \cdot l \cdot \Delta t$

If adiabatic conditions are realized, heat flow into or out of the sample via the ambient is avoided. Adiabatic conditions are assured with an adiabatic shield, surrounding the sample cell, and following the temperature evolution of the sample cell such that no more relevant temperature difference exists. Calorimeters using this principle are called adiabatic calorimeter ( $A C)$. A calibration of a sensor for heat flow is here not needed; the heat input by el. work is known from $\mathrm{P}_{\mathrm{el}}=\mathrm{U} \cdot \mathrm{I}$ with high accuracy. To correct for the heat capacity of the sample cell, a calibration of it by a separate experiment is done.

A drawback of $A C$ is that electric heating allows only measurements on heating, not on cooling. However, if small heat losses are allowed instead of completely adiabatic conditions, measurements can also be done on cooling. AC is used in different variations, e.g. depending on the variation of the electric heating with time.

To accurately measure heat capacity and enthalpy changes the classical Nernst heat pulse method [11] was used extensively in the past, using finite electric pulses, thus giving finite steps $\Delta \mathrm{Q}$. By adding consecutively small heat inputs, the enthalpy as a function of temperature can be obtained. Although tedious and time consuming, the method has been essential to determine accurate values of specific heat capacity over wide temperature ranges for a set of reference materials, e.g. synthetic sapphire and copper [12]. Often uncertainties of a few tenths of a percent are reported. Determination of latent heats, e.g. heat of fusion, is also possible $[12,13]$.

Adiabatic scanning calorimetry (ASC) was introduced in the 1970s, applying, under adiabatic conditions a constant electrical power to the sample (a crucial advantage when measuring latent heats compared to DSC, if operated at a constant rate of ambient temperature change). The result of ASC is a continuous heat capacity or enthalpy curve, compared to a discontinuous one when using heat pulses. Previous implementations of the ASC concept (e.g. [14-16]) required careful preparation and operation, which made ASC a method largely used in academia, operated by skilled and well-trained personnel. In a modern type of ASC these problems are eliminated by inserting, as a temperature difference detector between the sample and the adiabatic shield, a very sensitive semiconductormaterial-based Peltier element (PE) [17]. The $\mu \mathrm{K}$ sensitivity of the PE for temperature differences allows to maintain almost perfect equality of sample and shield temperature in heating mode. In the cooling mode, a preset temperature difference between the sample and the shield can be kept constant with equal resolution. In the older versions of the ASC concept samples from a few grams to a couple of hundred milligrams were used to achieve proper accuracy. In pASC (Peltier-element-based ASC) samples as small as a few tens of $\mathrm{mg}$ are used. Routinely liquid (or melting) substances enclosed in typically $100 \mu \mathrm{l}$ hermetically closed sample cells are used [18]. This size is similar to that of typical hf-DSC equipment. Recently, pASC has been used extensively for measuring reference materials like gallium [18] or biphenyl and phenyl salicylate [19], water and water-sodium chloride solutions [20], the n-alkanes C23 [21] and C26, C27, C28, C29, C30 [22], as well as the commercial PCM RT42 $([21,23])$.

\subsubsection{Calorimetric methods based on equipment for thermal conductivity measurement}

In addition to the calorimetric methods just discussed, methods to determine the thermal conductivity have been modified for calorimetric measurements, specifically to be able to measure large samples of PCM, PCM composites, or encapsulated PCM. This is necessary e.g. for quality control, as to test PCM content in an insulation material [24] or in macrocapsules. The methods used are heat flow meter (HFM), guarded hot plate (GHP), and longitudinal guarded comparative calorimeter.

In a calorimetric measurement, the heat flow into or out of a sample is measured. Heat flow meter (HFM), guarded hot plate (GHP), and longitudinal guarded comparative calorimeter are all methods to determine the thermal conductivity of a sample, where the heat flow into the 
sample on one side and out of the sample on the other is measured. In recent years, they have been tested also as calorimeters. For calorimetric measurements the conditions are changed such that the heat flow is in or out from both sides. They are thus non-conventional calorimetric methods, not developed for calorimetric measurements, but useful for the purpose with some modification. Information on calorimetric measurements on PCM by a heat flow meter (HFM), also called dynamic heat flow meter apparatus, is found in [25-27]. Wan et al. [28] describe the use of guarded hot plate (GHP). For the Longitudinal Guarded Comparative Calorimeter information is available in [29]. With regard to calibration, if needed, they are calibrated using reference materials for thermal conductivity. However, reference materials for $\Delta_{p c} h$ or $c_{p}$ are still needed for testing (reference materials for thermal conductivity can e.g. not test side losses or gains).

Calorimetric methods used for PCM thus cover a wide variety of equipment as well as measurement, calibration, and evaluation procedures. They differ significantly regarding the sample size, the general sample properties, the parameter range that they can cover, and of course the accuracy.

\subsection{State of the art measuring PCM}

\subsubsection{Basic terms of calorimetry regarding measurement and results}

To discuss calorimetric measurements and results a few terms are needed and thus introduced here.

First, to reflect $h(T)$ or $c_{p}(T)$ properly regarding $T$, the sample must be sufficiently close to isothermal conditions during a measurement; otherwise the heat exchanged cannot be attributed to a single T. In addition, to properly characterize a material, the sample must be representative of the material to be investigated.

Regarding the results of measurements, the "guide to the expression of uncertainty in measurement" (GUM) of the Joint Committee for Guides in Metrology [30] defines further, crucial terms. The true value of a quantity is the value consistent with the definition of the quantity. It would be obtained by a perfect measurement, which is impossible, therefore true values cannot be determined. The accuracy of a measurement refers to the closeness of the agreement between the result of a measurement and the true value in a qualitative way. To be able to assess the reliability of a result, a result should be accompanied by a quantitative indication of its quality by its uncertainty; the uncertainty reflects a lack of exact knowledge of a result, e.g. $10^{\circ} \mathrm{C} \pm 0.5^{\circ} \mathrm{C}, 150 \mathrm{~J} / \mathrm{g} \pm 15 \mathrm{~J} / \mathrm{g}$, or $150 \mathrm{~J} / \mathrm{g} \pm 10 \%$. Important is if the measurement result is repeatable, which refers to same conditions, and also if it is reproducible, which refers to different conditions. Reproducibility is crucial for using values from a measurement in an application at different conditions, but also when using different measurement methods, equipment etc. where sample size, pressure, or e.g. container walls are different.

\subsubsection{Required uncertainty for the results of calorimetric measurements on PCM}

The required uncertainty for results of calorimetric measurements on PCM depends on the application. Applications of PCM in buildings and in transport boxes can serve as examples.

The uncertainty of $\Delta_{\mathrm{pc}} \mathrm{h}$ should be less than $10 \%$, if possible $5 \%$. This is a balance between effort and demand. $10 \%$ is a value that is commonly achieved in calorimetric measurements used in R\&D on PCM, while $5 \%$ is reached by few, with significantly increased effort. At the same time, sensible heat and dynamic effects are present in real applications, and there is also always some variability in properties of different samples of the same material e.g. due to small changes in composition; therefore, the effort to achieve an uncertainty less than $5 \%$ in individual measurements is not justified.

The uncertainty in the temperature is important in applications regarding temperature stabilization and heat transfer. Regarding temperature stabilization, e.g. in transport boxes, requirements are usually given in integer values of $\mathrm{T} /{ }^{\circ} \mathrm{C}$. For heat transfer between $\mathrm{PCM}$ and ambient, e.g. at a temperature difference of $5^{\circ} \mathrm{C}$ an uncertainty of $0.5^{\circ} \mathrm{C}$ is needed to limit the uncertainty in heat transfer to $10 \%$. Thus an uncertainty of at least $1{ }^{\circ} \mathrm{C}$, better $0.5^{\circ} \mathrm{C}$, is desired.

\subsubsection{Achieved uncertainty, and used reference materials}

To discuss the need for new reference materials and the requirements on them it is necessary to look at the achieved uncertainty, and review which reference materials exist and which are used.

Today, activities exist worldwide and have resulted in experience with a number of calorimetric techniques, comprising diverse equipment, and different calibration and measurement procedures. Several standards for measurement, evaluation and data presentation/communication were developed. The oldest standard is the one of the RAL Quality Association PCM (available at http:// www.pcm-ral.org/pcm/en/quality-testing-specifications$\mathrm{pcm} /$ ). It covers several properties and corresponding measurement methods. It does not specify all details, e.g. calibration, because the monitoring institutes are well experienced in the individual methods used by them. Institutes working in PCM R\&D in most cases use hf-DSC for 
calorimetric measurements on PCM. A standard for them was developed within an IEA activity, the Task 42/Annex 29. The IEA standard comprises [31], specifically for hf-DSC, the determination of the appropriate heating and cooling rate to assure closeness to isothermal conditions in the sample, the calibration, the measurement itself, and the data analysis and representation. For calorimetric measurement of PCM using a HFM, an ASTM standard [26] was developed.

Testing the accuracy of measurement results is crucial to assess the reliability of data for applications. The immediate requirement is testing a specific measurement principle, method, procedure, etc. In addition, intercomparison tests, also called ring tests or round robin tests, test the agreement of results measured by different methods, equipment, procedures (calibration, measurement, evaluation) and/or people or institutes. Independent of the type of testing, a suitable material for testing must fulfill some requirements, to not pose a problem already on its own, such that it allows to just focus on the quality of the measurement. For this, the material must behave repeatable, thus not show any instability or irreversible behavior. It must also behave reproducible under the required conditions varied in the measurements, especially in intercomparison tests. This includes that representative samples can be taken for all sample sizes. In addition, the material must be safe, available in the required purity in sufficient amount and at reasonable price. A simple approach is using a certified reference material, where property values have been determined in intercomparison tests of professional institutes. The measured value can then be compared with the value of the reference material. For intercomparison tests, another option is selecting a material that is not a reference material, sometimes where even no property value is previously known, and just comparing the values resulting from the measurements.

With regard to the calibration and testing of individual equipment, the case of hf-DSC is the easiest. They are commonly calibrated by $\mathrm{Ga}$, In, and $\mathrm{Al}_{2} \mathrm{O}_{3}$, and sometimes by further reference materials. Direct testing is then often done by one of these reference materials. For T-history, there is a reference material with known $c_{p}$ used during measurement, usually water; others with $\mathrm{T}_{\mathrm{pc}}$ and $\Delta_{\mathrm{pc}} \mathrm{h}$ are used for testing. Lázaro et al. [9] e.g. describe the testing of a T-history setup designed for the temperature range of $-20^{\circ} \mathrm{C}$ to $+65^{\circ} \mathrm{C}$, and sample size from 15 to $150 \mathrm{ml}$, using $\mathrm{Ga}$, water, and hexadecane. Water melts at $0^{\circ} \mathrm{C}$, however is not a certified reference material regarding its melting enthalpy; the respective value of $333.5 \mathrm{~J} / \mathrm{g}$ was taken from available literature. For hexadecane, $18.1^{\circ} \mathrm{C}$ and $236 \mathrm{~J} / \mathrm{g}$ [32] were used. For higher temperatures two PCM melting around $27^{\circ} \mathrm{C}$ and $58^{\circ} \mathrm{C}$ were measured and their results compared to results from DSC measurements. To be able to measure water at temperatures $\mathrm{T}<0{ }^{\circ} \mathrm{C}, \mathrm{Al}_{2} \mathrm{O}_{3}$ was used as reference material for $c_{p}$ in the measurement. Rathgeber et al. [10] describe the calibration of a T-History calorimeter for measurements in the temperature range from 40 to $200^{\circ} \mathrm{C}$. Due to the temperature range, instead of water they use copper with its $c_{p}$ as reference material during all measurements. As only a few reference materials undergo a phase change within the operating temperature range, they used In and also three PCM where data from literature and DSC measurements were available. For the 3-layer calorimeter, $\Delta_{p c}$ h of hexadecane is used for calibration, using literature data. To be able to measure even larger samples, Göbel et al. [27] tested a commercially available heat flow meter, modified to be used for calorimetric measurements. The samples are plates of $20 \mathrm{~cm} \times 20 \mathrm{~cm}$ and variable thickness. The materials used for testing were stainless steel 1.0332 and a gypsum board with microencapsulated PCM melting around $28^{\circ} \mathrm{C}$; the samples had about $12 \mathrm{~mm}$ thickness, thus about $400 \mathrm{ml}$ volume. For both, reference data were taken from DSC measurement. For the stainless steel, using a temperature step between 19 and $29^{\circ} \mathrm{C}$, the mean specific heat capacity in the temperature range differed by less than $2 \%$ from the value determined by DSC. For the gypsum board with microencapsulated PCM, using a temperature step between 11 and $33^{\circ} \mathrm{C}$ to include the phase change, the enthalpy difference in the temperature range differed by less than $4 \%$ from value on the data sheet provided by the manufacturer.

The use of reference data from DSC measurements in several cases when testing within a lab already indicates some demand for reference materials. But before analyzing the situation, let's first complete things looking at intercomparison tests between labs using same or different calorimetric methods. Gschwander et al. [31] present results of an intercomparison test using hf-DSC within the IEA SHC Task 42/ECES Annex 29, at different laboratories using different devices. The material used for testing was laboratory-grade octadecane (Parafol 18-97, Sasol). After initially having large deviations in results, a measurement standard was developed telling how to take care of temperature gradients in the sample, calibration, and baseline instability. For calibration water, $\mathrm{Ga}$, and In are recommended. With the new procedure, the results of the final test that comprise samples of about 8-300 mg measured in different DSCs, show a standard deviation of $10 \%$ in enthalpy and $0.3^{\circ} \mathrm{C}$ in temperature. Vidi et al. [33] presents the results of an intercomparison test performed between the monitoring institutes of the RAL Quality Association PCM: the ZAE Bayern, the FhG-ISE, and w\&a. The test followed the standard of the RAL Quality Association PCM. The material used for the test was the commercial, paraffin based PCM RT8 HC (Rubitherm). The instruments used 
were, in order of increasing sample size, a hf-DSC $(\sim 10 \mu \mathrm{l})$ at the ZAE Bayern, a Calvet calorimeter $(\sim 100 \mu \mathrm{l})$ at the FhG ISE, a T-history setup $(\sim 10 \mathrm{ml})$ again at the ZAE Bayern, and a 3-layer calorimeter $(\sim 100 \mathrm{ml})$ by w\&a. The results show a very good agreement for the overall phase change enthalpy, ranging between 169 and $184 \mathrm{~kJ} / \mathrm{kg}$, thus with a total difference of $9 \%$. The peak temperatures of $c_{p}$ for heating are between 7.7 and $8.0^{\circ} \mathrm{C}$, thus differing by only $0.3^{\circ} \mathrm{C}$ (the samples are to be measured close to isothermal conditions, so comparing peak temperatures is a check of that). For cooling, they are between 6.7 and $8.0^{\circ} \mathrm{C}$.

\section{Reference materials: demand}

At a first glance, these results look quite good. All instruments are calibrated, reference materials for comparative measurements are available, tests could be performed, and test results are within the desired uncertainty. But things are not as satisfactory as they look at a first glance in general.

Let's start with calibration, as it was performed. Already in DSC measurements water has been used as reference material for $T_{p c}$ and $\Delta_{p c} h$, e.g. by Gschwander et al. [31]; this was done to have a third reference point besides $\mathrm{Ga}$ and In, so the temperature range around room temperature is included. But $\Delta_{p c}$ h of water is not a certified reference value; the value has just been taken from literature. And the same applies to hexadecane when used to calibrate the 3-layer calorimeter; it is not a certified reference material, and its value of $\Delta_{\mathrm{pc}} \mathrm{h}$ is just a literature value. In T-history a reference material for $c_{p}$ is measured in parallel with the sample, commonly water; its $c_{p}$ is a certified reference value. But only between 0 and $100^{\circ} \mathrm{C}$. To be able to measure below $0{ }^{\circ} \mathrm{C}$, Lázaro et al. [9] used $\mathrm{Al}_{2} \mathrm{O}_{3}$, which is a certified reference material. To be able to measure up to $200{ }^{\circ} \mathrm{C}$, Rathgeber et al. [10] used copper, however copper is not a certified reference material for $c_{p}$ above $300 \mathrm{~K}$. Also, while copper and $\mathrm{Al}_{2} \mathrm{O}_{3}$ have volume specific $c_{\mathrm{p}}$ similar to water (water $1.0 \mathrm{~g} / \mathrm{cm}^{3} \cdot 4.1 \mathrm{~J} / \mathrm{gK}=4.1 \mathrm{~J} / \mathrm{cm}^{3} \mathrm{~K}$, copper $8.9 \mathrm{~g} / \mathrm{cm}^{3} \cdot 0.39 \mathrm{~J} / \mathrm{gK}=3.5 \mathrm{~J} / \mathrm{cm}^{3} \mathrm{~K}$, and $\mathrm{Al}_{2} \mathrm{O}_{3} 3.9 \mathrm{~g} /$ $\mathrm{cm}^{3} \cdot 0.78 \mathrm{~J} / \mathrm{gK}=3.0 \mathrm{~J} / \mathrm{cm}^{3} \mathrm{~K}$ ), they involve some technical difficulties. Both are solid, therefore have a thermal contact resistance to the test tubes. In addition, $\mathrm{Al}_{2} \mathrm{O}_{3}$ as single crystal (synthetic sapphire) is far too expensive, and as powder or granulate has lower density and could absorb water, which could significantly alter the volumetric $c_{p}$. The situation regarding calibration is thus by far not as good in general as it looks at a first glance. And testing? Regarding testing by using certified reference materials the situation is the same as just discussed, as the materials are the same that are already used for calibration. To test
T-history equipment, Lázaro et al. [9] used $\mathrm{Ga}$, and water and hexadecane which are not certified reference materials, while Rathgeber et al. [10] used In. Overall, testing was done where certified reference materials were available, specifically by In and Ga; they were supplemented by water which is not a certified reference material for $\Delta_{p c} h$, and in intercomparison tests they were supplemented by results from DSC measurements on materials that are not certified reference materials. The results of the tests achieved the desired accuracy. Striking is that no test was done at all below $0{ }^{\circ} \mathrm{C}$, or above $100^{\circ} \mathrm{C}$.

We can summarize from the state of the art of current usage that

- Specifically for T-history, it would be good to have other reference materials for $\mathrm{c}_{\mathrm{p}}$ besides water, $\mathrm{Cu}$ and $\mathrm{Al}_{2} \mathrm{O}_{3}$, specifically materials which are liquid, for below $0{ }^{\circ} \mathrm{C}$ and for above $100^{\circ} \mathrm{C}$ where water cannot be used.

- In general, it would be good to have other reference materials for $T_{p c}$ and $\Delta_{p c} h$, besides $G a$ and In, especially as both are not cheap when needed in volumes of $10 \mathrm{ml}$ or more (e.g. it would be good to be able to use water as a reference material not only for $T_{p c^{\prime}}$ but also for $\Delta_{\mathrm{pc}} \mathrm{h}$ ).

But there are other, known certified reference materials, that have not been used. Why are they not used? Reference materials are applied for different purposes: for calibration, as reference materials in comparative measurements, and for testing of equipment including also inter-comparison tests. For all these usages, it is recommended that a reference material has similar properties as the samples to be measured, so it is necessary to look at the typical properties of PCM and not of materials in general. When a $c_{p}$ reference material is used for calibration, e.g. in T-history, this rule is violated; the reason is to get a calibration in a temperature range instead of just at temperature points. However, the value of $c_{p}$ per volume should be high, as it is for water. In addition, in comparative measurements the reference is often used for months, so container tightness and corrosive behavior do play a special role. Also, the different methods used to characterize PCM differ in sample/reference size, and suitable reference materials should cover the full size range, e.g. be representative, have low cost, no hazards...

For a reference material for $c_{p}$ in T-history, heptane, shown in Fig. 4, is a certified reference material, but it has a flash point of $4{ }^{\circ} \mathrm{C}$ such that it poses some fire danger, especially if test tubes are not sealed perfectly. The flash point is the lowest temperature at which vapor of a material will ignite when given an ignition source. In addition, its $c_{p}$ per volume is just half of that of water. Sabbah et al. 
[5] list further reference materials for $c_{p}$, which are also liquids like heptane and water: naphthalene, diphenyl-ether, polystyrene, polyvinyl chloride, benzene, hexafluorobenzene and nitrogen. But naphthalene, being liquid above $80^{\circ} \mathrm{C}$, has a flash point of only $80^{\circ} \mathrm{C}$. Diphenyl-ether, which is also liquid above $80^{\circ} \mathrm{C}$, has a flash point of $115^{\circ} \mathrm{C}$. Polystyrene is only liquid beyond $240^{\circ} \mathrm{C}$, and polyvinyl chloride is only liquid well beyond $100^{\circ} \mathrm{C}$. Benzene is liquid above $5{ }^{\circ} \mathrm{C}$, and has a boiling point of just $80^{\circ} \mathrm{C}$ and a flash point of $-11^{\circ} \mathrm{C}$. Hexafluorobenzene has similar properties, and nitrogen is only liquid below $-210^{\circ} \mathrm{C}$. All these materials are either not liquid in the required temperature range or are hazardous.

For $\mathrm{T}_{\mathrm{pc}}$ and $\Delta_{\mathrm{pc}} \mathrm{h}$ there are a number of other certified reference materials. Figure 4 shows mercury, cyclohexane, biphenyl, and naphthalene. No reference material below $0{ }^{\circ} \mathrm{C}$ is available, except mercury; but mercury should not be used for safety reasons in amounts of $10 \mathrm{ml}$ or more as is needed for T-history and 3-layer calorimeter. Cyclohexane has a flash point of $-18^{\circ} \mathrm{C}$, is thus also not safe, especially in large amounts and if vapors can be generated by leakage; its boiling point is $81^{\circ} \mathrm{C}$. Biphenyl has a low $\Delta_{\mathrm{pc}}$ h of about $125 \mathrm{~J} / \mathrm{cm}^{3}$ compared to PCM, but otherwise reasonable properties. Naphthalene has again a low flash point of $80^{\circ} \mathrm{C}$, making it not safe when handled in large amounts. Phenyl salicylate, not shown in Fig. 4 , has a low $\Delta_{\mathrm{pc}} \mathrm{h}$ of about $115 \mathrm{~J} / \mathrm{cm}^{3}$, and a flash point of $113^{\circ} \mathrm{C}$.

For comparison, hexadecane and octadecane, the two alkanes that have been used already, have the following values: hexadecane has a boiling point of $287^{\circ} \mathrm{C}$ and a flash point of $135^{\circ} \mathrm{C}$, octadecane has a boiling point of $316^{\circ} \mathrm{C}$ and a flash point of $166^{\circ} \mathrm{C}$. They are thus much safer to handle. And for water, where $\Delta_{\mathrm{pc}} \mathrm{h}$ is not a certified reference value, a value of $333.5 \pm 0.2 \mathrm{~J} / \mathrm{g}$ is available in literature $[13,34]$. These three materials could thus be potential new reference materials. But even if they are, they are not sufficient as they just cover a narrow temperature range.

\section{Potential new reference materials}

\subsection{Requirements for reference materials}

Reference materials are applied for different purposes: for calibration, as reference materials in comparative measurements, and for testing of equipment including also inter-comparison tests. For all these uses, a number of requirements exist in general. The requirements on a material to be suitable as reference material can be split in requirements regarding the selection of the material, the measurement of the property, and the presentation/ communication of the property data.

\section{Selection of a material}

In general, a material should pose no significant problem on measuring its property. This means it should not be hazardous or corrosive. It must also be available at the required composition, e.g. purity, at an acceptable price. For the measurement of the property by a wide range of instruments, parameters etc., the material must behave repeatable with regard to the property, meaning give the same result at same conditions, as well as reproducible, meaning at somewhat different conditions. E.g. the material must also allow to take representative samples for different sample sizes.

\section{Measurement of the property}

The property of the material must have been measured by experts in the field, with highly accurate measurements, testing specifically reproducibility, and a property value or value function has been accepted including uncertainty. The uncertainty of a reference material must be significantly lower than the uncertainty needed in common measurements to be useful for calibration etc.

3. Presentation/communication of the property data

The presented/communicated property data must include the specification of the material (composition, preparation...), the value or value function of the property including uncertainty, and maybe also the measurement method used and a reference where further information is found.

\subsubsection{Requirements for reference materials for calorimetric measurements on PCM}

What does this mean specifically for calorimetric measurements on PCM? First, reference materials are needed with regard to amounts of heat and temperature. Useful material properties are $T_{p c}$ and $\Delta_{p c} h$ of phase changes, and for amounts of heat also the specific heat capacity $c_{p}$.

\section{Selection of a material}

Calorimetric measurements on PCM are done using a wide variety of samples regarding size and even encapsulated PCM (e.g. for quality control), and very different methods and instruments. Reference materials are used for calibration, for comparison, and for testing, and at best are suitable for all these usages. To be useful in comparative measurements and intercomparison tests they must be useful for many measurements and for long time, meaning be perfectly repeatable. And to be useful for the variety of sample sizes and measurement conditions well reproducible, e.g. the material must allow to take representative 
samples for a wide range of sample sizes. It is critical that the material is available in the required composition; e.g. how does the value of $c_{p}, T_{p c^{\prime}}$ or $\Delta_{p c}$ h change with composition? The el. conductivity of semiconductors is very sensitive to impurities, while the density of paraffins is not. For $T_{p c^{\prime}} \Delta_{p c} h$, and $c_{p^{\prime}}$, this should be tested by comparing a highly pure sample with one of lower purity, e.g. for paraffins $99 \%$ or better to $98 \%$. Also related are the cost, even for sample size of $100 \mathrm{ml}$ or above (500 $\mathrm{ml}$ for HFM).

Because of the sample size, and the construction of the various instruments, a reference material should also have low vapor pressure e.g. to prevent the hazard of combustible vapors in large amounts, not diffuse (diffusion loss in crucibles), not change its composition or that of containers by corrosion, not change its composition if in contact with air (not be hygroscopic, not oxidize). For a specific selection, a reference material should have a similar property value as the samples to be measured. For PCM this means $\Delta_{\mathrm{pc}}$ h should be higher than $150 \mathrm{~J} / \mathrm{g}$ or $150 \mathrm{~J} / \mathrm{ml}$, and $T_{p c}$ in the range of interest. The thermal conductivity can be low; common liquid PCM have below $1 \mathrm{~W} / \mathrm{mK}$. Furtheron, materials with close peaks that cannot clearly be resolved into separate peaks by the calorimetric measurements used for PCM are not useful. When a $c_{p}$ reference material is used for calibration, e.g. in T-history, this rule is violated somewhat; the reason is to get a calibration in a temperature range instead of just at temperature points. However, the value of $c_{p}$ per volume should be high, as it is for water.

\section{Measurement of the property}

For a reference material for $c_{p}, T_{p c}$ or $\Delta_{p c} h$ in calorimetric measurements, the respective value or value function needs to be measured by experts in the field with highly accurate calorimeters, testing specifically reproducibility, and result in an accepted property value or value function including uncertainty. Specifically, for PCM, what does that mean?

For amounts of heat, a measurement should have an uncertainty of $5 \%$ as discussed previously. The uncertainty of a reference material must be significantly lower, e.g. $3 \%$; this could comprise a contribution of $1 \%$ from the sample (material) e.g. by its composition (e.g. purity), $2 \%$ from the measurement of the property, and $0 \%$ from the presentation/communication of the property data. For temperature, a measurement should have an uncertainty of $0.5^{\circ} \mathrm{C}$ as discussed previously. Let's assume an uncertainty of $0.3^{\circ} \mathrm{C}$ at most for a reference material; this could comprise a contribution of $0.2^{\circ} \mathrm{C}$ from the sample (material), $0.1^{\circ} \mathrm{C}$ from the measurement of the property, and $0.0^{\circ} \mathrm{C}$ from the presentation/communication of the property data.

\section{Presentation/communication of the property data}

The presented/communicated property data must include the specification of the material (composition, preparation...), the value or value function of the property including uncertainty, and maybe also the measurement method used and a reference where further information is found. In general, the use of material property data just from data tables is thus not recommended. Usually, neither the precise composition (e.g. purity) is given, nor the uncertainty of the measurement, and also not how values were read from the measured curve, meaning what given data refer to exactly. All these effects are reflected by the range of values found for $c_{p}, T_{p c}$ and $\Delta_{p c}$ h of materials in literature.

How $c_{p}, T_{p c^{\prime}}$ or $\Delta_{p c}$ h were determined from the measured data is especially critical if the measured data show a phase change temperature range. Let's first look at the origin, and then on how to deal with it.

If the true behavior of a material is phase change in a temperature range (Fig. 2), the result of a measurement (if having sufficiently dense data points) shows the phase change in a temperature range. In that case, a single value of $T_{p c}$ does not exist. The RAL and the IEA standard, who focus on data for heat storage applications, therefore require to give the stored heat in temperature intervals, e.g. of $1{ }^{\circ} \mathrm{C}$, thus $\Delta \mathrm{h}$ for each interval. This is the thermal effect in any application and avoids misunderstandings. The reason for a true behavior with a phase change temperature range are impurities in the material, in the extreme case even leading to phase separation during phase change. To avoid this, thus to have for true behavior an ideal phase change (Fig. 1), commonly certified reference materials are highly pure. Their true behavior on phase change is a single value of $\mathrm{T}_{p c^{\prime}}$ and $\Delta_{p c} \mathrm{~h}$ is the corresponding step in $\mathrm{h}(\mathrm{T})$.

However, even if the true behavior is ideal, this is still often not the direct result of a measurement. One reason is the necessary T-gradient within the sample for heat transfer in or out of its full volume. The sample is thus never fully isothermal. However, its temperature is detected only at a single point. In a scanning measurement with constant dT/ $\mathrm{dt}$, as used commonly in hf-DSC, this can lead to significant artificial peak widening, thus that even if the true behavior of the sample material is ideal phase change a significant peak width is observed in the measurement result. This is why many common reference materials have a high thermal conductivity, meaning they are of the class of metals. In addition, the sample temperature is determined e.g. at the surface of the sample crucible (in hf-DSC sometimes even the reference crucible), such that there is an additional temperature shift along the thermal resistance in 
between. Thus, for measurements with hf-DSC, small dT/ $\mathrm{dt}$ are recommended to assure close to isothermal conditions, or optionally to use $\Delta \mathrm{T}$ steps that limit the effect to the step size. The effects are generally well known; Hiebler [35] describes and studies it specifically for hf-DSC. The slow heating used in ASC limits the effect such that it does not become relevant. Only in $\mathrm{AC}$ measurements that use $\Delta Q$ steps an ideal phase change can be observed at a single temperature $\mathrm{T}_{\mathrm{pc}}$.

Consequently, that measured data show a phase change temperature range is quite common, and practically always the case if using hf-DSC, even if measuring highly pure materials. Thus, it is necessary to discuss how $c_{p}, T_{p c}$ or $\Delta_{p c}$ h are determined from the measured data. A measurement result with a finite peak width shows Fig. 5: $h(T)$ and corresponding $c_{p}(T)$, incl. characteristic temperatures.

Values for $T_{p c^{\prime}} \Delta_{p c} h$, and $c_{p}$, to be read from the experimental results, are often hard to identify. Most critical are $\mathrm{T}_{\mathrm{pc}}$ and $\Delta_{\mathrm{pc}} \mathrm{h}$; less critical is $c_{\mathrm{p}}$ outside the phase change because there $c_{p}(T)$ changes little. The extrapolated onset, peak, or offset of $c_{p}(T)$ are e.g. used to "define" $T_{p c}$ (Fig. 5). The onset does not vary with heating rate, thus it is often used if the heating rate strongly affects the peak width. If impurities have a significant effect on the onset of heating, but not the heating rate (e.g. in AC or ASC) other points in the peak are used (e.g. Table 1). For $\Delta_{p c}$ h, one option is to use the whole enthalpy change from start to end, as indicated by the shaded area in Fig. 5 at the top. But if using hf-DSC, with increasing heating rate the end of phase change is shifted further into the range of the liquid phase, as discussed above, thus $\Delta_{\mathrm{pc}} \mathrm{h}$ between the start and end T increases with the heating rate (and the same for cooling). The same holds if the on- and offset temperature are used. This is quite common when using hf-DSC, including for calibration. For example, at a $c_{p}$ of $2 \mathrm{~J} /(\mathrm{g} \cdot \mathrm{K})$ a peak width of $1 \mathrm{~K}$ already gives $2 \mathrm{~J} / \mathrm{g}$, thus a difference of $1 \%$ for a phase change enthalpy of $200 \mathrm{~J} / \mathrm{g}$. It is thus common to integrate the peak just to a peak baseline, as shown in Fig. 5 center or bottom. This results in $\Delta_{\mathrm{pc}} \mathrm{h}$ values that vary far less with the heating rate. Different methods exist to construct a peak baseline. E.g. based on the assumption of having a true ideal phase change, the peak width in $c_{p}(T)$ reflects a gradual change of phase such that the fraction of the shaded area of the peak on the left and right of a temperature gives the fraction of the phases; this is called the $1 / F$ (extrapolation) method $[20,36]$. If the phase change is not ideal, it just reflects the fraction of the peak's enthalpy. Another option shows Fig. 5 bottom, assuming constant $c_{p}$ to the peak temperature.

The effect is small if the peak is sharp, thus materials with high thermal conductivity are preferable as reference material. However, this is not the case with materials like water, hexadecane, or octadecane. Also, measurements
Fig. 5 Measurement result with a finite peak width: $h(T)$, corresponding $c_{p}(T)$, and ways of reading data

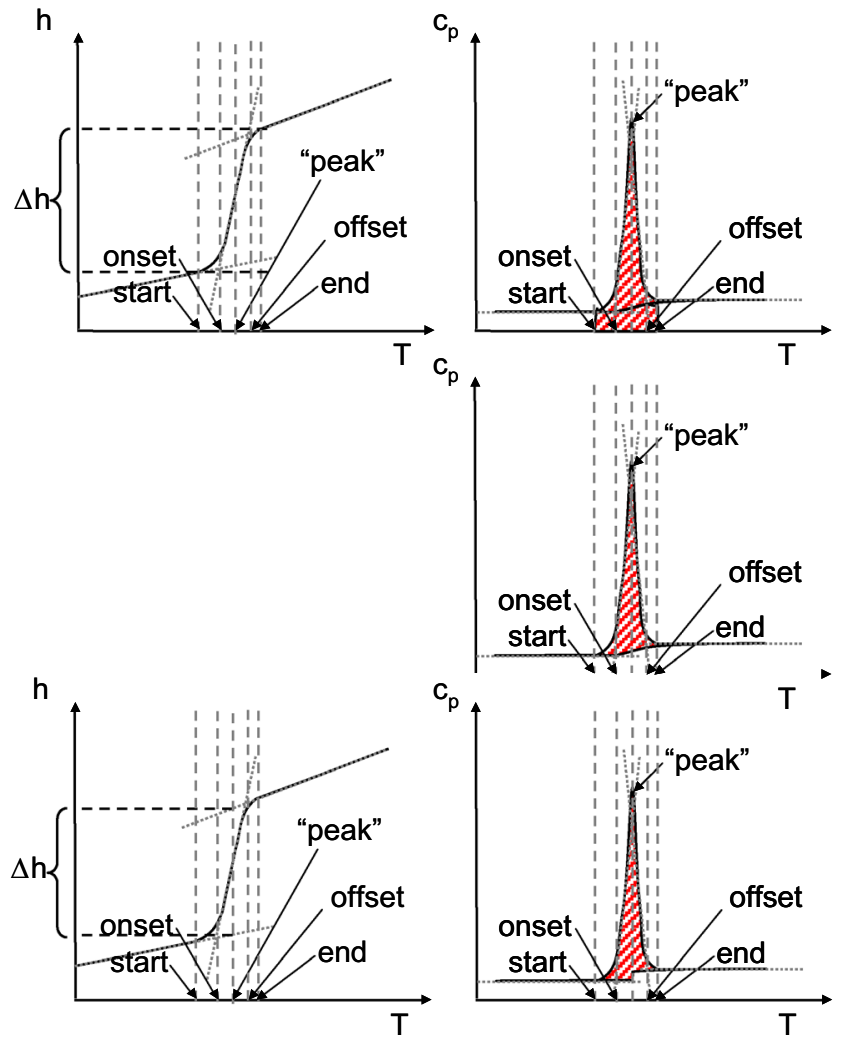

integration to the physical baseline of zero heat flow

integration to a peak baseline constructed, e.g. based on the fraction of phases for ideal phase change

integration to a peak baseline constructed, here from linear extrapolation of $c_{p}$ to the peak temperature 
in DSC or T-history often give different curves on heating and cooling (Fig. 7), and even different curve shapes compared e.g. to pASC (tetradecane in Figs. 7 and 8) due to differences in heat flow and temperature measurement. Data reading and presentation/communication is thus susceptible to significant misinterpretations. A solution of the problem comprises two things. First, measurements must be in a way that assures the sample is sufficiently close to isothermal conditions to reduce the peak width, and materials should be pure. Second, the values of $\Delta_{p c} h$ and $\mathrm{T}_{\mathrm{pc}}$ must be accompanied by a description of the way they were determined from the measured curves.

\subsubsection{Suitable calorimetric methods, equipment, and available literature data}

An uncertainty of $2 \%$ in amounts of heat and $0.1{ }^{\circ} \mathrm{C}$ in temperature or better, as needed, cannot be attained with most calorimetric methods and equipment. Hemminger et al. [37] discuss this, and they recommend for high precision calorimetry to use adiabatic calorimetry as the prime choice. As adiabatic calorimeters are rare worldwide, they recommend, if a larger uncertainty is acceptable, DSC calibrated by absolutely measured reference materials, or calibrated by an electrical source, if possible.

Therefore, a search was performed by the first author in journal publications and on institute websites to find well-documented measurements by $\mathrm{AC}$, or people using $A C$ being able to do measurements. While few welldocumented measurement results are published, the research group of the coauthors at KU Leuven, which uses adiabatic scanning calorimetry (ASC) was found. The ASC is self-developed, built, and tested, using a Peltier element to assure adiabatic conditions, thus called pASC. Leys et al. [18] describe it in detail, and state that the uncertainty on the absolute values of specific heat capacity and enthalpy is about $2 \%$. The pASC has been tested on several certified reference materials for $T_{p c}$ and $\Delta_{\mathrm{pc}} \mathrm{h}$. For gallium, Leys et al. [18] measured two samples, both giving $29.79{ }^{\circ} \mathrm{C}$ while Della Gatta et al. [4] report (certified reference materials, Tab. 2) a value of $29.780^{\circ} \mathrm{C}$, respectively $82.4 \pm 2 \mathrm{~J} / \mathrm{g}$ and $82.1 \pm 2 \mathrm{~J} / \mathrm{g}$ compared to $80.14 \pm 0.17 \mathrm{~J} / \mathrm{g}$ which is reported by [4]. For biphenyl, Leys et al. [19] report values of $68.98^{\circ} \mathrm{C}, 68.99^{\circ} \mathrm{C}$, and $68.97^{\circ} \mathrm{C}$ compared to $68.93^{\circ} \mathrm{C}$ given by Della Gatta et al. [4], and respectively $122.9 \mathrm{~J} / \mathrm{g}, 122.5 \mathrm{~J} / \mathrm{g}, 122.1 \mathrm{~J} / \mathrm{g}$ compared to $120.6 \pm 0.8 \mathrm{~J} / \mathrm{g}$. Leys et al. [19] report also results for phenyl salicylate and a comparison with values given by Della Gatta et al. [4]. Altogether, all measurements show a deviation from the certified reference value for $T_{p c}$ of less than $0.1{ }^{\circ} \mathrm{C}$, and for $\Delta_{p c}$ h of about $2 \%$ or less. This is within the required accuracy as discussed previously.

Further measurements on several other materials have been published by the research group at KU Leuven, including uncertainty of the results, composition of the materials, effect of change of composition etc. Some of these materials seem suitable to be used as reference materials for calorimetric measurements on PCM. These serve as a basis for the further discussion; where available, suitable data on other materials and measurement results of other groups are added.

\subsection{New options for reference materials for $T_{p c^{\prime}} \Delta_{p c} h$}

In general, materials with close peaks that cannot clearly be resolved into separate peaks by the calorimetric measurements used for PCM are not useful; peaks should be clearly at least $5{ }^{\circ} \mathrm{C}$ apart. Water, hexadecane, and octadecane have already been used occasionally to test calorimetric equipment used for measuring PCM, so these could be useful candidates. Water seems to be especially suitable as it is already used as reference material, however just for $T_{p c}$ and $c_{p}$, and not for $\Delta_{p c} h$, so it fulfills many requirements. And it is also a PCM and has similar properties to many other PCM. Besides hexadecane and octadecane, the $\mathrm{n}$-alkanes are in general materials that are very promising; they are inert, and they are already used as PCM. Hexadecane and octadecane are just two examples. We will start looking at these candidates.

\subsubsection{Water}

Water seems to be suitable as it is already used as reference material, however just for $T_{p c}$ and $c_{p}$, and not for $\Delta_{p c} h$, so it fulfills many requirements. And it is used as a PCM, and has similar properties to many other PCM. Data of $c_{p}, T_{p c^{\prime}}$ and $\Delta_{p c} h$ can be found in many sources. For $c_{p}(T)$ and $T_{p c}$ a detailed discussion is found in [5], including uncertainty and required purity. For $\Delta_{\mathrm{pc}} \mathrm{h}$, which is not a certified reference value, Dickinson et al. [38] present an early review. Dickinson et al. [39] then describe a correction of previous measurements on water, which was purified by repeated distillation and measured by several methods; the result was $79.74 \mathrm{cal} / \mathrm{g}$, being equal to $333.9 \mathrm{~J} / \mathrm{g}(1 \mathrm{cal}=4.187 \mathrm{~J})$. Osborne [34] later gives a value of $333.5 \pm 0.2 \mathrm{~J} / \mathrm{g}$, which is still in close agreement. Later, Archer [13] published new data consistent with the older literature and suggested to use water as reference material also for $\Delta_{\mathrm{pc}} \mathrm{h}$.

Leys et al. [20] present pASC measurements (heating) of highly pure (Fisher) water (Fig. 6, left), and comparison with water of different purity (right): Spa water and a diluted salt solution with 0.1388 mass $\%$ of $\mathrm{NaCl}$. The results (Table 1) for $\Delta_{p c}$ h all agree within $2 \%$ with the 

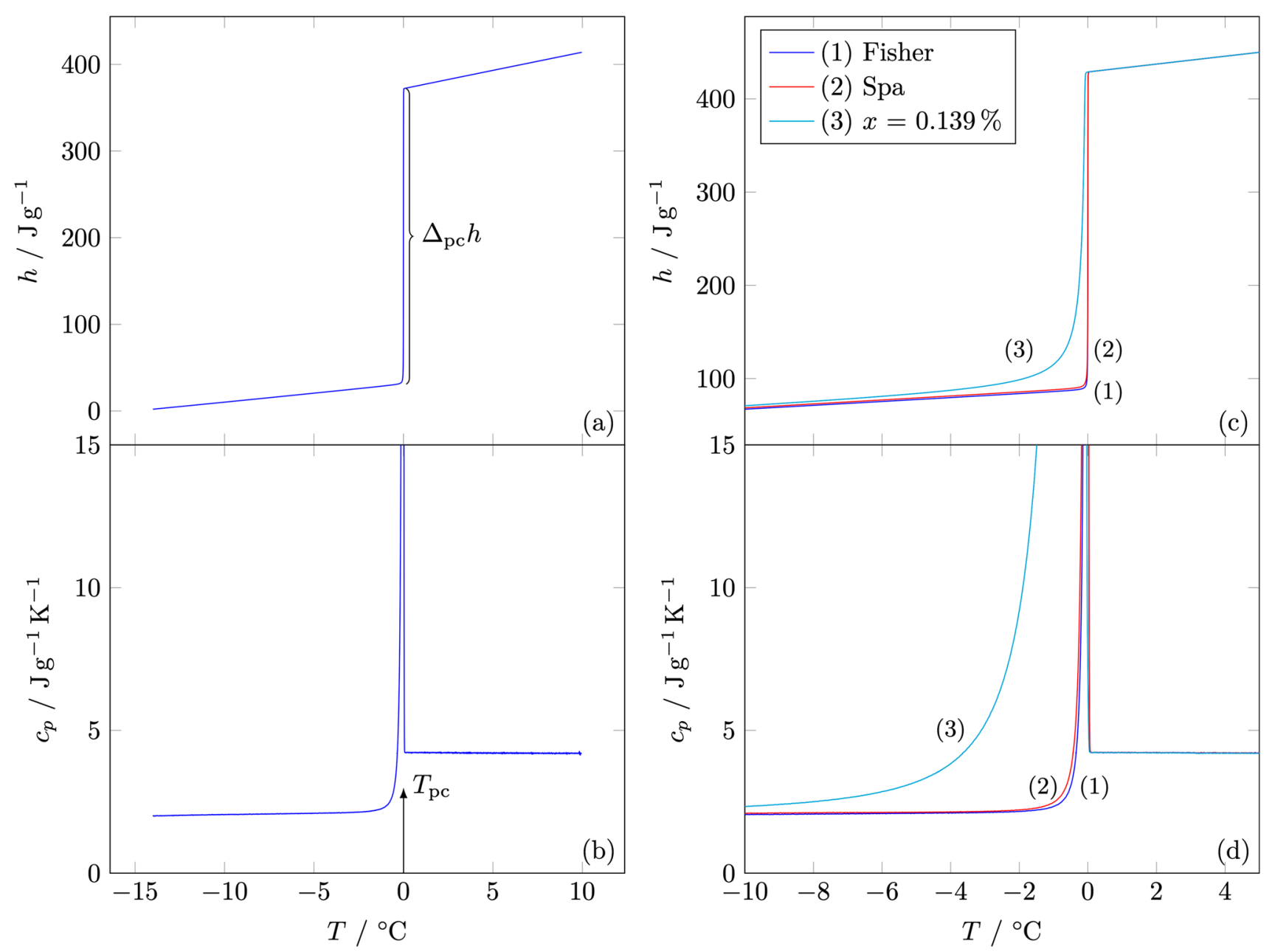

Fig. 6 Results of pASC measurements on highly pure (Fisher) water (left), and comparison with water of different purities (right): Spa water and a diluted salt solution with 0.1388 mass $\%$ of $\mathrm{NaCl}$ Source: [20]

Table 1 Water data from Leys et al. [20]

\begin{tabular}{lllll}
\hline$\#$ & Name & $\mathrm{x}_{\mathrm{m}}$ in mass $\%$ & $\mathrm{~T}_{\mathrm{pc}}$ in ${ }^{\circ} \mathrm{C}$ & $\Delta_{\mathrm{pc}} \mathrm{h}$ in J/g \\
\hline 1 & Fisher & 0 & 0.005 & 340.7 \\
2 & Spa & 0 & 0.005 & 338.9 \\
3 & & 0.1388 & -0.078 & 335.3 \\
\hline
\end{tabular}

The transition temperatures were obtained from the intersection of the extrapolations of the $h(T)$ data in the upper transition region and the higher temperature phase. The transition enthalpies were obtained following the procedure of "calculation of the molten fraction".

literature values given above. The variation of purity shows that within the required uncertainty for $\mathrm{T}_{\mathrm{pc}}$ and $\Delta_{\mathrm{pc}} \mathrm{h}$, the required purity (composition) is not critical. $T_{p c^{\prime}}$ determined from the intersection of the extrapolations of the $h(T)$ data in the upper transition region and the higher temperature phase, also agrees very well.
Water has a repeatable and reproducible behavior, a suitable value of $\Delta_{p c} h$ and $T_{p c}$ in the required range, is available in the required composition at acceptable price, and information on how $\mathrm{T}_{\mathrm{pc}}$ and $\Delta_{\mathrm{pc}}$ h vary with composition is available. It poses no hazards, has a low vapor pressure, and is compatible with containers and air exposure (hygroscopic, oxidation...). The measurement of the property for $\Delta_{\mathrm{pc}}$ h shows a variation by composition $<1 \%$ (Fischer and Spa water) and $\leq 2 \%$ by uncertainty of the value (comparison of the values from [20] with those of [34]), for $\mathrm{T}_{\mathrm{pc}}$ a variation by composition $<0.2^{\circ} \mathrm{C}$ and $<0.1^{\circ} \mathrm{C}$ by uncertainty of the value. The presentation/communication of the property data includes the specification of the material (composition, preparation...), the value or value of the property including uncertainty, and also the measurement method used and a reference where further information is found. Water, as already suggested by Archer [13], is thus 
Fig. $7 h(T)$ curves from DSC measurements on $\mathrm{n}$-alkanes with a chain length of $\mathrm{C}$-atoms between 12 and 28 , at the top for even numbers, and at the bottom for odd numbers Source: [40]
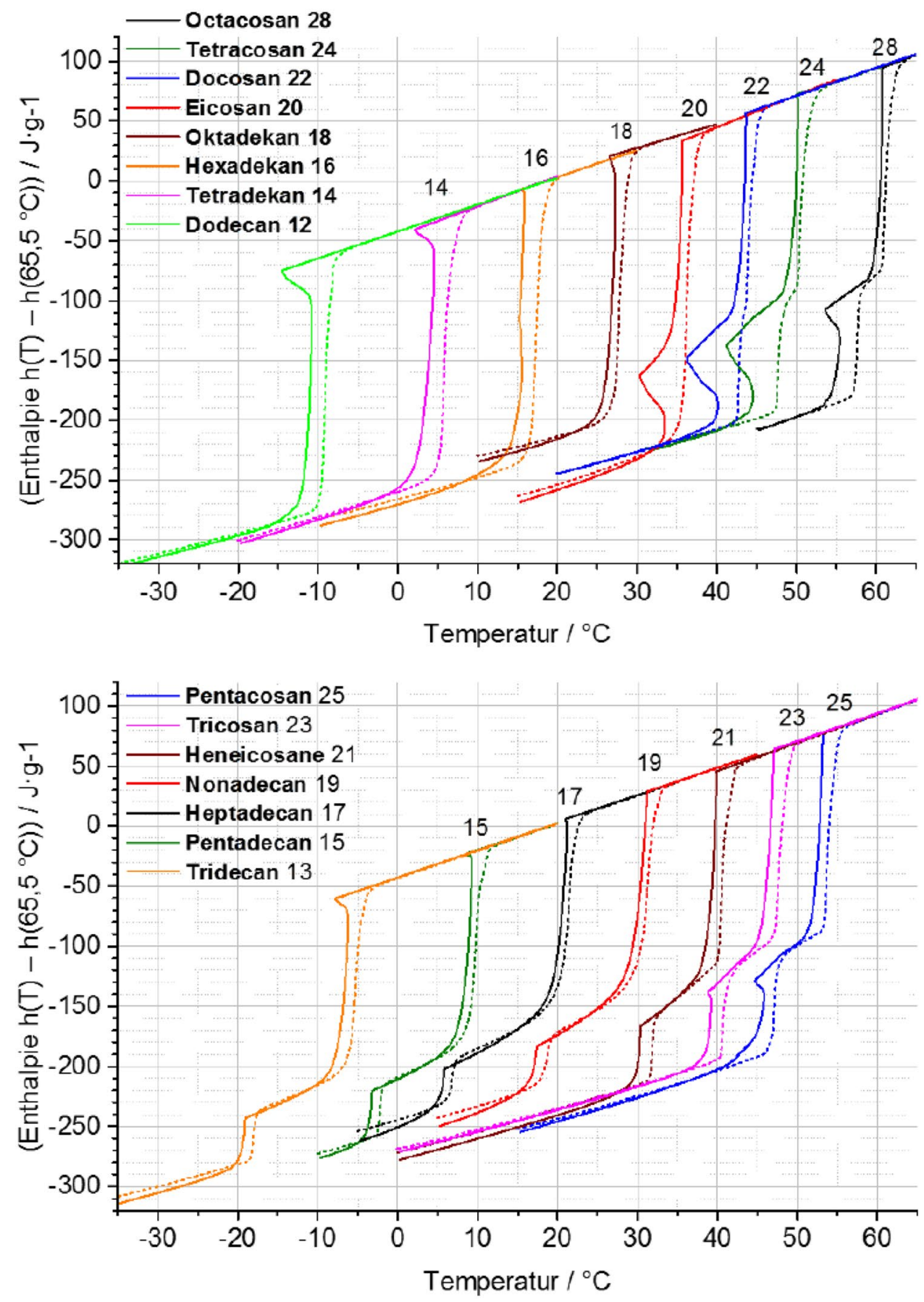

useful as reference material for measurements of $T_{p c}$ and $\Delta_{\mathrm{pc}}$ h, e.g. on PCM.

\subsubsection{Overview on n-alkanes}

Fig. 7 shows an overview on $\mathrm{h}(\mathrm{T})$ curves of a number of $\mathrm{n}$-alkanes that have phase transitions between -20 and $+60^{\circ} \mathrm{C}$, taken from [40], which is the final report of a public funded project.

\section{SN Applied Sciences}

The data show $h(T)$ curves from heating and cooling measurements using hf-DSC on n-alkanes with a chain length of C-atoms between 12 and 28 (C26 and C27 are missing), at the top for even and at the bottom for odd numbers. The heating and cooling rates were chosen between 0.5 and $2{ }^{\circ} \mathrm{C} / \mathrm{min}$ (based on the RAL criterion that a sufficiently small rate is reached when, after halving the heating rate and halving it again, the temperatures at the inflection points of the heating measurements deviate no more than $0.2 \mathrm{~K}$ from each other). 
Table 2 Values for dodecane, from the NIST Chemistry WebBook (the values in $\mathrm{J} / \mathrm{g}$ have been calculated here using the molar weight of 170.3348 from the NIST Chemistry WebBook)

\begin{tabular}{llll}
\hline$\Delta_{\mathrm{pc}} \mathrm{h}$ in $\mathrm{kJ} / \mathrm{mol}$ & $\Delta_{\mathrm{pc}} \mathrm{h}$ in J/g & $\mathrm{T}_{\mathrm{pc}}$ in K & Method \\
\hline 36.836 & 216.25 & 263.59 & $\mathrm{~N} / \mathrm{A}$ \\
35.7 & 209 & 263.1 & $\mathrm{DSC}$ \\
36.82 & 216.2 & 263.6 & $\mathrm{~N} / \mathrm{A}$ \\
36.581 & 214.74 & 263.5 & $\mathrm{~N} / \mathrm{A}$ \\
\hline
\end{tabular}

The results can be used to make three groups:

- Group 1 shows single transitions; it comprises $\mathrm{C} 12, \mathrm{C} 14$, C16, and C18.

- Group 2 shows transitions more than $5 \mathrm{~K}$ apart; it comprises $\mathrm{C} 13, \mathrm{C} 15, \mathrm{C} 17, \mathrm{C} 19$, and C21.

- Group 3 shows transitions less than $5 \mathrm{~K}$ apart; it comprises $\mathrm{C} 20, \mathrm{C} 22, \mathrm{C} 23, \mathrm{C} 24, \mathrm{C} 25$, and C28.

For the search for new reference materials for $T_{p c}$ and $\Delta_{p c} h$, the first group with single transitions is most promising. It includes hexadecane, which is already used to calibrate the 3-layer calorimeter, and also octadecane, which was used in the IEA intercomparison test for hf-DSC as the sample material. The second group is less promising, because it is only useful if the user of a potential reference material can clearly separate the peaks; this should still be possible with calorimetric methods used for PCM if used properly. The third group has transitions less than $5 \mathrm{~K}$ apart, which are not promising.

The following discussion focuses on the group 1, materials with single transitions and thus most promising. It comprises $\mathrm{C} 12, \mathrm{C} 14, \mathrm{C} 16$, and C18. In Tables 2-5 typical values from the NIST Chemistry WebBook are presented; further data can be found in a review by Acree and Chickos [41].

\subsection{3 n-alkane dodecane C12}

No reliable source for data of $\mathrm{T}_{\mathrm{pc}}$ and $\Delta_{\mathrm{pc}} \mathrm{h}$ with high accuracy was found, including purity and effect of its variation,

Table 3 Values for tetradecane, from the NIST Chemistry WebBook (the values in $\mathrm{J} / \mathrm{g}$ have been calculated here using the molar weight of 198.3880 from the NIST Chemistry WebBook)

\begin{tabular}{llll}
\hline$\Delta_{\mathrm{pc}} \mathrm{h}$ in $\mathrm{kJ} / \mathrm{mol}$ & $\Delta_{\mathrm{pc}} \mathrm{h}$ in J/g & $\mathrm{T}_{\mathrm{pc}}$ in K & Method \\
\hline 45.070 & 227.18 & 279.03 & $\mathrm{~N} / \mathrm{A}$ \\
42.7 & 215 & 278.3 & $\mathrm{DSC}$ \\
45.07 & 227.18 & 279 & $\mathrm{~N} / \mathrm{A}$ \\
\hline
\end{tabular}

Table 4 Values for hexadecane, from the NIST Chemistry WebBook (the values in $\mathrm{J} / \mathrm{g}$ have been calculated here using the molar weight of 226.4412 from the NIST Chemistry WebBook)

\begin{tabular}{llll}
\hline$\Delta_{\mathrm{pc}} \mathrm{h}$ in $\mathrm{kJ} / \mathrm{mol}$ & $\Delta_{\mathrm{pc}} \mathrm{h}$ in J/g & $\mathrm{T}_{\mathrm{pc}}$ in K & Method \\
\hline 47.545 & 209.97 & 292.1 & $\mathrm{~N} / \mathrm{A}$ \\
53.359 & 235.64 & 291.34 & $\mathrm{~N} / \mathrm{A}$ \\
53.0 & 234 & 290.7 & $\mathrm{DSC}$ \\
51.46 & 227.3 & 291.1 & $\mathrm{~N} / \mathrm{A}$ \\
51.543 & 227.62 & 291.1 & $\mathrm{~N} / \mathrm{A}$ \\
\hline
\end{tabular}

Table 5 Values for octadecane, from the NIST Chemistry WebBook (the values in $\mathrm{J} / \mathrm{g}$ have been calculated here using the molar weight of 254.4943 from the NIST Chemistry WebBook)

\begin{tabular}{llll}
\hline$\Delta_{\mathrm{pc}} \mathrm{h}$ in $\mathrm{kJ} / \mathrm{mol}$ & $\Delta_{\mathrm{pc}} \mathrm{h}$ in J/g & $\mathrm{T}_{\mathrm{pc}}$ in K & Method \\
\hline 61.500 & 241.66 & 301.5 & $\mathrm{~N} / \mathrm{A}$ \\
60.760 & 238.75 & 301.0 & $\mathrm{~N} / \mathrm{A}$ \\
61.706 & 242.47 & 301.33 & $\mathrm{~N} / \mathrm{A}$ \\
60.1 & 236.2 & 301.1 & $\mathrm{DSC}$ \\
61.5 & 242 & 301.3 & $\mathrm{~N} / \mathrm{A}$ \\
60.484 & 237.66 & 301.3 & $\mathrm{~N} / \mathrm{A}$ \\
\hline
\end{tabular}

thus no reliable data for the use of dodecane as reference material for $T_{p c}$ and $\Delta_{p c} h$. [42] lists the values shown in Table 2 . The values of $\Delta_{\mathrm{pc}} \mathrm{h}$ vary by $5.74 \mathrm{~J} / \mathrm{g}$ between max. and $\mathrm{min}$. (209 J/g and $214.74 \mathrm{~J} / \mathrm{g}$ ), thus about $2.7 \%$, while those of $\mathrm{T}_{\mathrm{pc}}$ vary by $0.5 \mathrm{~K}$ between max. and $\min$. $(263.1 \mathrm{~K}$ and $263.6 \mathrm{~K}$ ). For $\mathrm{T}_{\mathrm{pc}}$ [42] also lists a value for separate data (without $\Delta_{\mathrm{pc}} \mathrm{h}$ ), which is $263.5 \pm 0.3 \mathrm{~K}$ (approx. $-9.6{ }^{\circ} \mathrm{C}$, average of 35 values). The data scatter significantly compared to the desired uncertainty of $2 \%$ in amounts of heat, and far compared to the $0.1^{\circ} \mathrm{C}$ in temperature.

\subsection{4 n-alkane tetradecane $\mathrm{C} 14$}

For tetradecane [43] lists the values shown in Table 3. Values of $\Delta_{\mathrm{pc}}$ h vary by $12.18 \mathrm{~J} / \mathrm{g}$ between max. and min. $(227.18 \mathrm{~J} / \mathrm{g}$ and $215 \mathrm{~J} / \mathrm{g})$, thus about $5.5 \%$, while those of $\mathrm{T}_{\mathrm{pc}}$ vary by $0.7 \mathrm{~K}$ between max. and min. ( $279.03 \mathrm{~K}$ and $278.3 \mathrm{~K}$ ). For $\mathrm{T}_{\mathrm{pc}}$ [43] also lists a value for separate data (without $\Delta_{\mathrm{pc}} \mathrm{h}$ ), which is $278.7 \pm 0.9 \mathrm{~K}$ (approx. $5.6^{\circ} \mathrm{C}$, average of 31 values). The data scatter rather far, compared to the desired uncertainty of $2 \%$ in amounts of heat and the $0.1^{\circ} \mathrm{C}$ in temperature.

The data from [43] do not show if a value of $\mathrm{T}_{\mathrm{pc}}$ or $\Delta_{\mathrm{pc}} \mathrm{h}$ has a high accuracy or not, not the purity of the sample, and thus also not the effect of its variation on $\mathrm{T}_{\mathrm{pc}}$ or $\Delta_{\mathrm{pc}} \mathrm{h}$.

In an early attempt at KU Leuven in 2013 [44] to apply the novel pASC to first-order phase transitions, measurements were carried out on a C14 sample of $66.56 \mathrm{mg}$ 


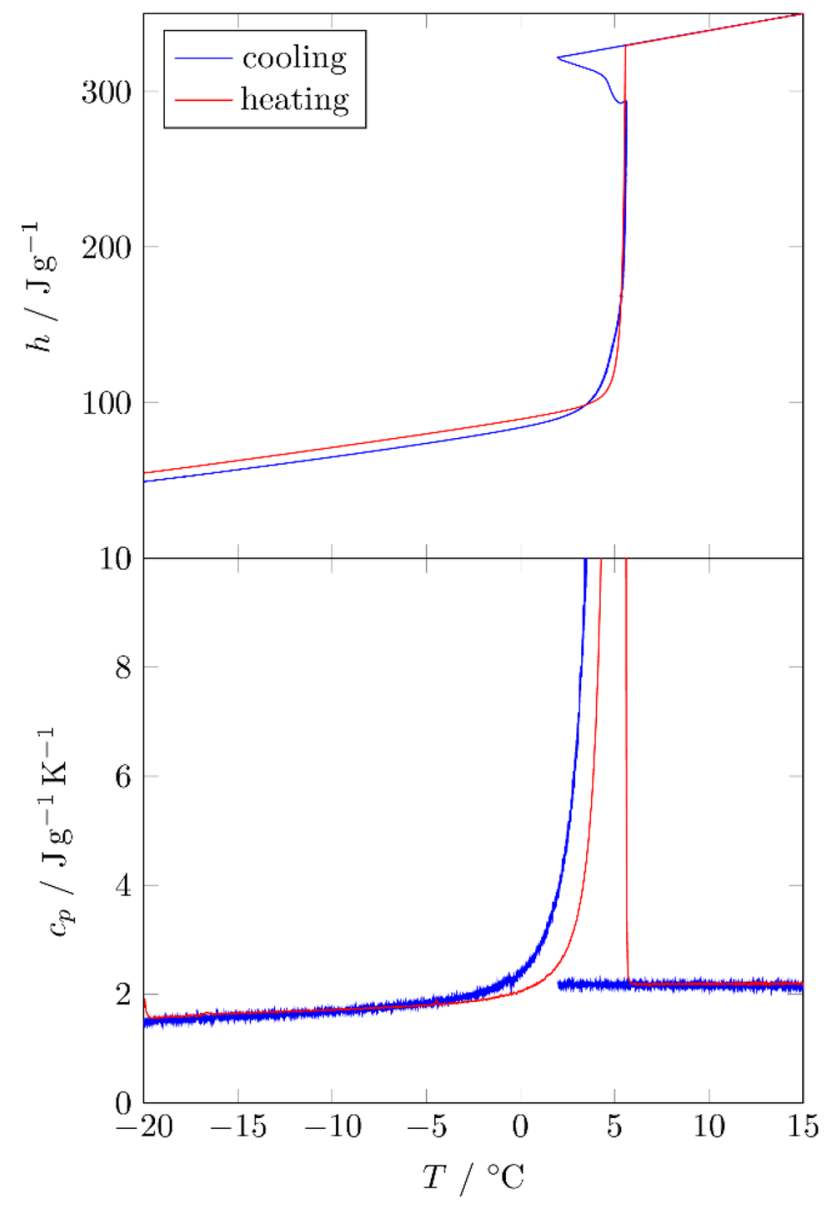

Fig. 8 Specific enthalpy (top) and specific heat capacity (bottom) as a function of temperature from pASC heating and cooling runs on a $82 \mathrm{mg}$ sample around the solid to liquid phase transition of n-tetradecane (C14)

(from Sigma Aldrich, 99.5\% pure) in a standard DSC cell. Only data for a heating run were obtained, resulting in a transition heat of $223 \pm 2 \mathrm{~J} / \mathrm{g}$. Recently, new results were obtained with pASC at KU Leuven on a new C14 (Aldrich $99+\%) 82.0 \mathrm{mg}$ sample, both in heating and cooling at an average heating rate of about $15 \mathrm{mK} / \mathrm{min}$ and average cooling rate of about $24 \mathrm{mK} / \mathrm{min}$ (average rate because the power is kept constant but the rate is inversely proportional to the heat capacity). In Fig. 8 results for the specific enthalpy $h(T)$ and the corresponding effective specific heat capacity $c_{p}(T)$ are displayed. The transition temperature obtained on heating is $5.60 \pm 0.03^{\circ} \mathrm{C}(278.75$ $\pm 0.03 \mathrm{~K})$. The same transition temperature is obtained on cooling, however, only after first supercooling by $3.7^{\circ} \mathrm{C}$ to a temperature of $1.9^{\circ} \mathrm{C}$. To obtain the transition heat the $I / F$ method $[18,36]$ was applied to the heating data. This resulted in a value of $229.7 \mathrm{~J} / \mathrm{g}$ for the heat of fusion. This value corresponds well with two values of Table 3 , but is also about $5 \%$ larger than the DSC value given in that table. If one derives a heat of fusion from the cooling data of Fig. 8 a 2\% larger value is obtained, which is acceptable in view of some thermal instability encountered during rapid solidification from supercooling.

Can tetradecane now be recommended as a reference material? Tetradecane has a repeatable and reproducible behavior, suitable values of $T_{p c}$ and $\Delta_{p c} h$, and is available in the required composition (e.g. purity) at an acceptable price. It has a flash point of $100^{\circ} \mathrm{C}$ and a boiling point of $254^{\circ} \mathrm{C}$, and has good compatibility with containers and air exposure (hygroscopic, oxidation...). These properties make tetradecane an interesting candidate. Reliable data for $T_{p c}$ and $\Delta_{p c} h$ with high accuracy, including purity and effect of its variation, are however only available from $\mathrm{KU}$ Leuven. And here the values of $\Delta_{\mathrm{pc}} \mathrm{h}$ discussed above $(223 \mathrm{~J} / \mathrm{g}$ and $229.7 \mathrm{~J} / \mathrm{g}$ ) vary by about $3 \%$. Thus, it seems advisable to do more research on the effect of purity, before tetradecane could be used as a reference material.

\subsection{5 n-alkane hexadecane C16}

Hexadecane, as mentioned, has already been used as calibration material for the 3-layer calorimeter, and to test T-history equipment by Lazaro et al. [9].

No reliable source for data of $\mathrm{T}_{\mathrm{pc}}$ and $\Delta_{\mathrm{pc}} \mathrm{h}$ with high accuracy was found, including purity and effect of its variation, thus no reliable data for the use of hexadecane as reference material for $T_{p c}$ and $\Delta_{p c} h$. [45] lists the values shown in Table 4. The values of $\Delta_{\mathrm{pc}} \mathrm{h}$ vary by $25.67 \mathrm{~J} / \mathrm{g}$ between max. and $\min$. (235.64 J/g and $209.97 \mathrm{~J} / \mathrm{g}$ ), thus about $11.6 \%$, while those of $\mathrm{T}_{\mathrm{pc}}$ vary by $1.4 \mathrm{~K}$ between max. and $\min$. (292.1 K and 290.7 K). For $\mathrm{T}_{p c}$ [45] also lists a value for separate data (without $\Delta_{\mathrm{pc}} \mathrm{h}$ ), which is $291 \pm 1 \mathrm{~K}$ (approx. $17.9^{\circ} \mathrm{C}$, average of 52 values). The data scatter rather far compared to the desired uncertainty of $2 \%$ in amounts of heat and $0.1{ }^{\circ} \mathrm{C}$ in temperature. For comparison, the values used by Lazaro et al. [9], taken from [32], were $18.1^{\circ} \mathrm{C}$, thus $291.25 \mathrm{~K}$, and $236 \mathrm{~J} / \mathrm{g}$.

\subsection{6 n-alkane octadecane $\mathrm{C} 18$}

Octadecane was already used in the IEA intercomparison test for hf-DSC as the sample material. But no reliable source for data of $\mathrm{T}_{\mathrm{pc}}$ and $\Delta_{\mathrm{pc}}$ h with high accuracy was found, including purity and effect of its variation, thus no reliable data for the use of octadecane as reference material for $T_{p c}$ and $\Delta_{p c} h$. [46] lists the values shown in Table 5. The values of $\Delta_{p c}$ h vary by $6.27 \mathrm{~J} / \mathrm{g}$ between max. and min. $(242.47 \mathrm{~J} / \mathrm{g}$ and $236.2 \mathrm{~J} / \mathrm{g})$, thus about $2.6 \%$, while those of $\mathrm{T}_{p c}$ vary by $0.5 \mathrm{~K}$ between max. and $\min$. (301.5 K and $301.0 \mathrm{~K}$ ). For $\mathrm{T}_{\mathrm{pc}}$ [46] also lists a value for separate data (without $\Delta_{\mathrm{pc}} \mathrm{h}$ ), which is $301.0 \pm 0.7 \mathrm{~K}$ (approx. $27.9^{\circ} \mathrm{C}$, average of 35 values). The data scatter significantly compared 
to the desired uncertainty of $2 \%$ in amounts of heat and rather far compared to $0.1^{\circ} \mathrm{C}$ in temperature.

Data from [46] do not show if a value of $\mathrm{T}_{\mathrm{pc}}$ or $\Delta_{\mathrm{pc}} \mathrm{h}$ has a high accuracy or not, not the purity of the sample, and thus also not the effect of its variation on $T_{p c}$ or $\Delta_{p c} h$. This is better in other data.

The sample used in the IEA intercomparison test for hfDSC was a commercial Parafol 18-97 (97\%). The Fraunhofer ISE, who took part in the intercomparison test and also organized it, has in the meantime measured samples of various purity: Parafol 18-97 (97 \%) from Sasol and n-octadecane $99.5 \%$ from Alfa Aesar. The following values shown in Fig. 9 are from their measurements with a MikroDSCIII (Calvet DSC), sample masses $234 \mathrm{mg}$ (99.5\%) and $272 \mathrm{mg}$ (97\%), 3rd cycle, $0.05 \mathrm{~K} / \mathrm{min}$.

As discussed in section "Suitable calorimetric methods, equipment, and available literature data", DSC calibrated by absolutely measured reference materials, or calibrated by an electrical source, is preferable. The MikroDSCIII is calibrated for heat flow by an electrical source (Joule effect calibration). It was again tested before the measurements on octadecane, using water, $\mathrm{Ga}$, and In, and the result was about $1.5 \%$ too high enthalpies (heat of fusion), using a sigmoidal peak baseline.

The results in Fig. 9 show for heating and for cooling a significant difference (hysteresis), indicating that the samples were still not fully isothermal (still lower heating/cooling rates are however prohibitive). There is the expected difference due to purity in the onset of melting. In addition, the sample with the lower purity also seems to have a slightly lower enthalpy change, in the order of $5 \mathrm{~J} / \mathrm{g}$. The peak integral, using a peak baseline by extrapolation of $c_{p}$ in the solid, is about $240 \mathrm{~J} / \mathrm{g}$. The value, and the variation with purity, corresponds well with the values in the NIST Chemistry WebBook.

Based on these results a discussion of the suitability of octadecane as reference material is possible. Octadecane,

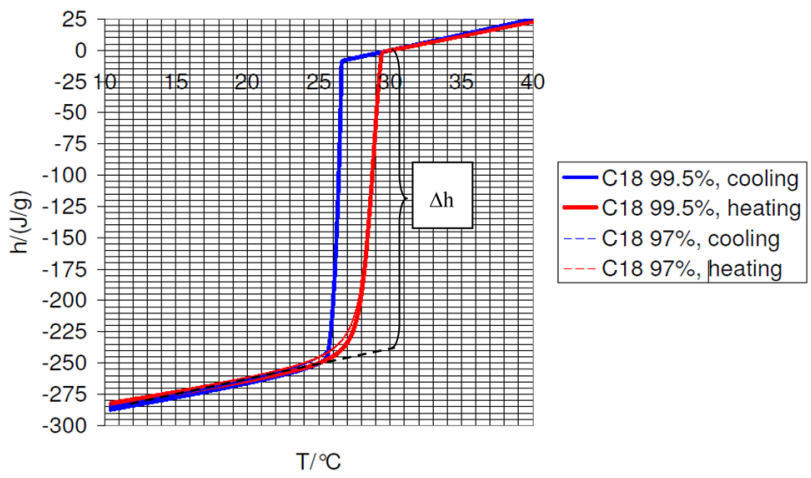

Fig. 9 Values of $\mathrm{h}(\mathrm{T})$ for octadecane of different purity, measured by the Fraunhofer ISE using a MikroDSCIII (Calvet DSC); the values are normalized to $0 \mathrm{~J} / \mathrm{g}$ at $30^{\circ} \mathrm{C}$ as is well known, has a repeatable and reproducible behavior, suitable $\Delta_{\mathrm{pc}}$ h above $150 \mathrm{~J} / \mathrm{g}$, and $\mathrm{T}_{\mathrm{pc}}$ in the required range. It is available in the required purity at acceptable price. Using the new measurements from the Fraunhofer ISE information how $T_{p c}$ and $\Delta_{p c} h$ vary with purity is available. Octadecane poses no hazards, has low vapor pressure, high flashpoint, and is compatible with containers and air exposure (hygroscopic, oxidation...). The values from the Fraunhofer ISE show a $\Delta_{\mathrm{pc}}$ h variation with purity from 97 to $99.5 \%$ by about $2 \%(5 \mathrm{~J} / \mathrm{g}$ of $240 \mathrm{~J} / \mathrm{g}$ ); a limitation to < $1 \%$ at $>99 \%$ purity thus seems probable. The uncertainty of a measurement is probably in the order of $2 \%$, as deviations by $1.5 \%$ for the enthalpies of water, $\mathrm{Ga}$, and In in the preceding tests show. Still investigated should be how the peak is integrated, due to the significant peak width. In contrast to $\Delta_{\mathrm{pc}}$ h, the data from the measurements by the Fraunhofer ISE do not allow a conclusion regarding $T_{p c}$. The data in [46] from an average of 35 values show approx. $27.9 \pm 0.7^{\circ} \mathrm{C}$, and this range is well within the options when reading a value from the curves in Fig. 9 from an onset or offset. The cause of this should be the variation with composition for the onset, and for the offset (of the heating curve) the fact that the sample might not have been sufficiently close to isothermal conditions. The latter is a general problem when using DSC with a constant heating rate, independent of the material. However it is not a general problem of calorimetric methods used for measuring PCM. Therefore, overall, octadecane could possibly be useful as reference material for $\Delta_{p c} h$ as well as for $T_{p c}$.

\subsubsection{Summary and further options}

The $\mathrm{n}$-alcanes $\mathrm{C} 12, \mathrm{C} 14, \mathrm{C} 16$, and C18, would probably be suitable as reference materials for $\mathrm{T}_{p c}$ and $\Delta_{p c} \mathrm{~h}$ at about $-9.6{ }^{\circ} \mathrm{C}, 5.6{ }^{\circ} \mathrm{C}, 17.9{ }^{\circ} \mathrm{C}$, and $27.9{ }^{\circ} \mathrm{C}$, as soon as for all of them suitable measurement data are available. In addition comes water at $0{ }^{\circ} \mathrm{C}$. Looking at Fig. 7 it is thus reasonable to skip the $\mathrm{n}$-alcanes $\mathrm{C} 13, \mathrm{C} 15, \mathrm{C} 17$, and $\mathrm{C} 19$, as they would cover the same temperature range while having somewhat more complex melting behavior; they were all summarized in group 2. Left from group 2 is only C21, with a $T_{p c}$ somewhat higher than those covered by $\mathrm{C} 12, \mathrm{C} 14, \mathrm{C} 16$, and $\mathrm{C} 18$. The group 3 materials were already excluded because of close double peaks.

Nevertheless, the temperature range between about $-10^{\circ} \mathrm{C}$ and about $30^{\circ} \mathrm{C}$ would be covered well. Below this temperature range there is currently only mercury, which is not safe when large samples are needed, thus there is still demand for options for reference materials at temperatures below $-10^{\circ} \mathrm{C}$. Regarding the temperatures above $30^{\circ} \mathrm{C}$, in section 3 it was discussed why biphenyl might be suitable for larger samples, while naphthalene is not considered safe. Indium in large amounts 
is too expensive. So there is still demand for options for reference materials at temperatures above $+30^{\circ} \mathrm{C}$.

Other classes of materials that are used as PCM, and available in high purity, are the $n$-alkanols and the $n$-carboxylic acids. However, the materials from both groups are polar, thus should be hygroscopic, which can cause trouble in keeping them free of water. In addition, the functional groups make them more reactive. In this first attempt to find new options for reference materials they are thus not investigated. Due to the required reproducibility, no salthydrates, no salt-water eutectics, and no salts for higher temperature are considered as reference materials for $\mathrm{T}_{\mathrm{pc}}$ and $\Delta_{\mathrm{pc}} \mathrm{h}$; these materials are all hygroscopic and well known for difficulties in controlling their composition.

\subsection{New options for reference materials for $c_{p}$}

Besides new options for reference materials for $T_{p c}$ and $\Delta_{p c} h$, it is still worth looking again at options for $c_{p}$, which can also be used to calibrate amounts of heat.

\subsubsection{Water-salt mixtures}

Water is a certified reference material for $c_{p}$, but limited by the solid-liquid and liquid-vapor phase transition to temperatures between 0 and $100{ }^{\circ} \mathrm{C}$ (Fig. 4). Addition of salts is known to reduce the freezing point and to raise the boiling point (reduce the vapor pressure). At the same time, $c_{p}$ could still be not much lower than for pure water. By adding salt to water, its applicable temperature range as a reference material for $c_{p}$ might thus be extended.

Leys et al. [20] measured eutectic and diluted mixtures of $\mathrm{NaCl}$ in water. Figure 10 shows the reduction of the freezing point, down to about $-21.1^{\circ} \mathrm{C}$ where the eutectic point is, such that the liquid phase is extended more than $20^{\circ} \mathrm{C}$ below zero.

The overview in Fig. 10 also shows again some things discussed earlier, related to Fig. 5. First, the addition of some impurities (e.g. $0.139 \%$ compared to $0 \%$ ) readily changes the temperature behavior at the onset of melting but not at its end, and second, the enthalpy difference between an extrapolated $c_{p}$ between liquid and solid phase is also initially not much affected. Thus these approaches can lead to the values of $\mathrm{T}_{\mathrm{pc}}$ and $\Delta_{\mathrm{pc}} \mathrm{h}$ of the pure substance, here water, in case of a practically isothermal sample. If the sample is not isothermal, as for DSC measurements with constant heating rate typical, the end of melting is shifted to higher temperatures, e.g. in Fig. 9 to about $29.5^{\circ} \mathrm{C}$ instead of just about $27.9^{\circ} \mathrm{C}$.

For a better evaluation the $h(T)$ graph in Fig. 10, from the original publication, is not very suitable. Thus, Fig. 11 shows the specific heat capacity $c_{p}(T)$, calculated from the data from Leys et al. [20]. The data are consistent with those of a more extensive data set found in [47], which show $c_{p}(T)$ measured on cooling even into the supercooled region, in contrast to the data from Leys et al. [20] that have been measured on heating from below the eutectic temperature $\left(-21^{\circ} \mathrm{C}\right)$ starting from the solid phase. In the region of overlap with the Archer data the agreement is better than $3 \%$.

The exact eutectic composition of water-salt mixtures is hard to prepare, because they are hygroscopic, and already the base salt for the mixture is rarely completely water free. Therefore, they do not seem to be suitable as reference materials for $T_{p c}$ and $\Delta_{p c} h$. However, for $c_{p}$ of the liquid phase the composition does not seem to be too critical. For example, in Fig. 11 at about $0{ }^{\circ} \mathrm{C}$ the value of $\mathrm{c}_{\mathrm{p}}$ changes from about $4.2 \mathrm{~J} /(\mathrm{g} \cdot \mathrm{K})$ for the pure water $(0 \%)$ to about $3.3 \mathrm{~J} /(\mathrm{g} \cdot \mathrm{K})$ for the $23.2 \%$ solution. The change of $0.9 \mathrm{~J} /(\mathrm{g} \cdot \mathrm{K})$ in $\mathrm{c}_{\mathrm{p}}$ per $23 \%$ change of salt concentration means roughly on average $0.038 \mathrm{~J} /(\mathrm{g} \cdot \mathrm{K})$ per $\%$ of salt, and with an average $c_{p}$ of the solutions of some $3.8 \mathrm{~J} /(\mathrm{g} \cdot \mathrm{K})$ it means roughly $1 \%$ change in $c_{p}$ per $1 \%$ change in salt concentration. Preparing mixtures with sufficiently accurate concentration should be possible, such that a near eutectic composition might be suitable as a reference material for $c_{p}$ in its liquid phase, at least to temperatures down to may be $-15^{\circ} \mathrm{C}$ (Fig. 11). This would already be a significant improvement e.g. for T-history measurements,
Fig. 10 Overview on $\mathrm{h}(\mathrm{T})$ of $\mathrm{NaCl}$-water mixtures up to the eutectic at $23.2 \mathrm{wt} \%$ Source: [20]

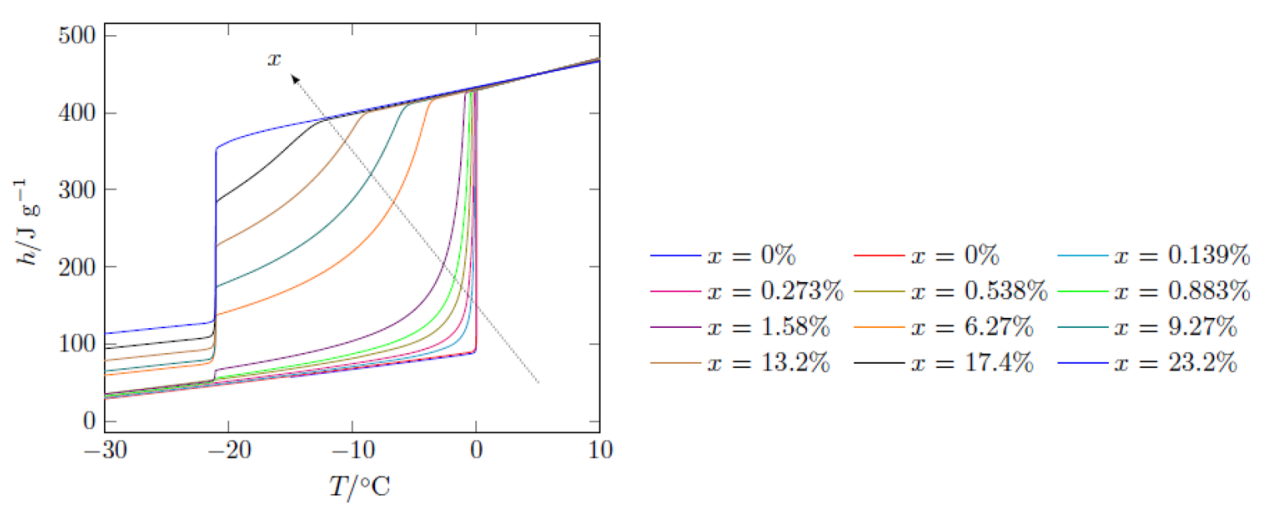




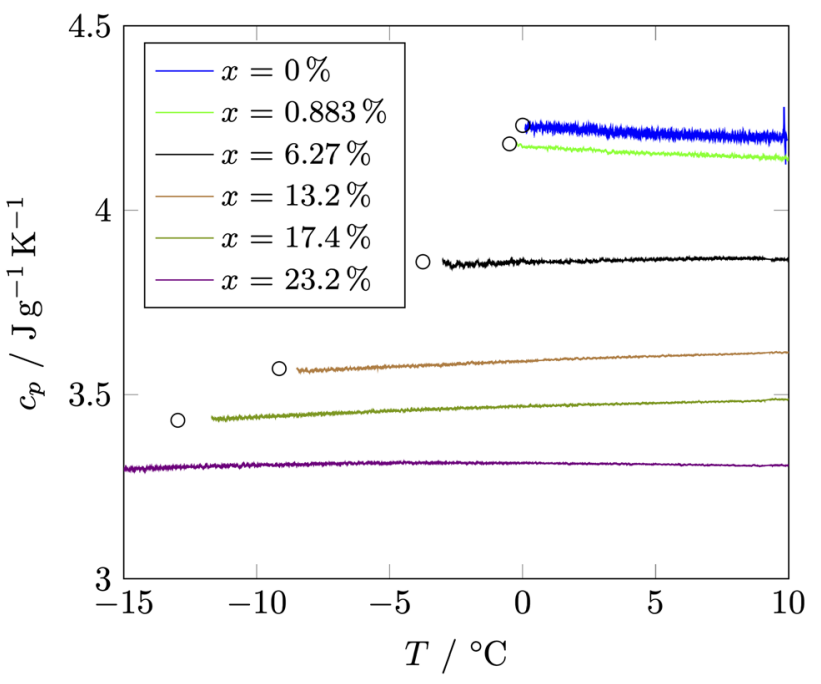

Fig. 11 Specific heat capacity $\mathrm{c}_{\mathrm{p}}(\mathrm{T})$ of $\mathrm{NaCl}$-water mixtures of various $\mathrm{NaCl} w t \%$, calculated from the data from [20]. The open circles represent the end of the melting peak in heating runs.

because currently, if using liquid water as reference for $c_{p}$, temperatures below $0{ }^{\circ} \mathrm{C}$ cannot be reached.

Besides $\mathrm{NaCl}$, of course also other salts could be suitable. However, water-salt mixtures can be corrosive depending on where they are used. Thus it is worth looking at two more options for reference materials for $c_{p}$ besides water-salt mixtures: water-alcohol mixtures, and the n-alkanes.

\subsubsection{Water-alcohol mixtures}

Water-salt mixtures, as with $\mathrm{NaCl}$, are corrosive to many metals, thus a second, similar option could be interesting: water-alcohol mixtures. Several of them are known as heat transfer fluids like water-salt mixtures, e.g. mixtures of water with methanol, ethanol, ethylene glycol, or propylene glycol.

For example, according to the Engineering ToolBox [48], a mixture of 60 vol.\% ethylene glycol in water does not freeze until $-52{ }^{\circ} \mathrm{C}$, has at $0{ }^{\circ} \mathrm{C}$ a density of $1.11 \mathrm{~g} / \mathrm{cm}^{3}$ and a heat capacity of $3.027 \mathrm{~J} / \mathrm{gK}$, and at $-40^{\circ} \mathrm{C}$ a density of $1.12 \mathrm{~g} / \mathrm{cm}^{3}$ and heat capacity of $2.847 \mathrm{~J} / \mathrm{gK}$. The $\mathrm{c}_{\mathrm{p}}$ at $0{ }^{\circ} \mathrm{C}$ is just $3.266 \mathrm{~J} / \mathrm{gK}$ for $50 \mathrm{vol} . \%$ and $2.931 \mathrm{~J} / \mathrm{gK}$ at $65 \mathrm{vol} . \%$, thus varies just about $0.022 \mathrm{~J} / \mathrm{gK}$ per vol.\%.

\subsection{3 n-alkanes}

Figure 4 shows that liquid heptane $\mathrm{C} 7$ is a certified reference material for $c_{p}$ [5], however it has a flashpoint of only $4{ }^{\circ} \mathrm{C}$, which makes it unsafe if large amounts of vapor can form. Nevertheless, it is straightforward to look for higher temperatures at $\mathrm{n}$-alkanes with longer chain length. For example, hexadecane has a boiling point of $287^{\circ} \mathrm{C}$ and a flash point of $135^{\circ} \mathrm{C}$, and octadecane has a boiling point of $316^{\circ} \mathrm{C}$ and a flash point of $166^{\circ} \mathrm{C}$. They are thus much safer to handle.

Vélez et al. [49] studied n-hexadecane C16, n-octadecane $\mathrm{C} 18$ and $\mathrm{n}$-eicosane $\mathrm{C} 20$ by hf-DSC, up to about $70{ }^{\circ} \mathrm{C}$, with good agreement to values of other references, and determined a polynomial expression for the $c_{p}$ in the solid and liquid phase for each material. Vélez et al. [50] repeated the same for $n$-pentadecane $C 15$, $n$-heptadecane $\mathrm{C} 17$ and n-nonadecane C19 by hf-DSC. While the data shown in Fig. 7 give the impression as if the value of $c_{p}$ (inclination of $h$ ) in the liquid phase is the same for all materials, the data of [49] and [50] show very similar $c_{p}$ for all six n-alkanes in the liquid phase at the same temperature, but with a slight, continuous increase of $c_{p}$ with the temperature. It could thus be speculated that $c_{p}$ in the liquid phase of $n$-alcanes is practically independent of the chain length; in literature, usually the same value is found for all paraffins. And maybe this then even applies to mixtures of them, which would reduce the demand of purity when taking a sample as reference. One of the references that were used by Vélez et al. [49] and [50] to compare their measurement results with those of others is van Miltenburg [51]. He gives data for the molar $c_{p}$ of liquid $n$-alkanes from pentane $\mathrm{C} 5$ to hexacosane $\mathrm{C} 26$. More important, he gives a function of temperature and number of carbon atoms in the chain that describes the experimental data to within the experimental error (the average percentage deviation is $0.18 \%$ ):

$c_{p}=\{43.9+13.990 \cdot(n-1)+0.05430 \cdot(n-1) \cdot T\} \cdot J K^{-1} \mathrm{~mol}^{-1}$

This allows a comparison of the molar $c_{p}$ values as a function of temperature and number of $\mathrm{C}$-atoms, and using the molar mass then the mass specific $c_{p}$. The result for the range of $n$ covered by [51] shows Table 6 . It shows that for $n \geq 10$ the difference between alcanes at the same temperature is within $2 \%$.

It could thus be interesting to study the n-alkanes further, also regarding the sensitivity of their $c_{p}$ in the liquid phase to impurities from other $n$-alkanes. A significant drawback of the $n$-alkanes, compared to water-salt solutions, is however the lower specific heat capacity per mass, and the lower density, which in combination lead to much lower specific heat capacity per volume; thus also per sample. 
Table 6 Mass specific $c_{\mathrm{p}}$ in $\mathrm{J} / \mathrm{gK}$ of $n$-alkanes calculated using the function from van Miltenburg [51]

\begin{tabular}{lllllll}
\hline$n$ & $\mathrm{~T} / \mathrm{K}$ & & & & & \\
\cline { 2 - 6 } & 300 & 320 & 340 & 360 & 380 & 400 \\
\hline 5 & 2.29 & 2.35 & 2.41 & 2.47 & 2.53 & 2.59 \\
6 & 2.27 & 2.33 & 2.40 & 2.46 & 2.52 & 2.59 \\
7 & 2.26 & 2.32 & 2.39 & 2.45 & 2.52 & 2.58 \\
8 & 2.24 & 2.31 & 2.38 & 2.44 & 2.51 & 2.58 \\
9 & 2.24 & 2.30 & 2.37 & 2.44 & 2.51 & 2.57 \\
10 & 2.23 & 2.30 & 2.37 & 2.43 & 2.50 & 2.57 \\
11 & 2.22 & 2.29 & 2.36 & 2.43 & 2.50 & 2.57 \\
12 & 2.22 & 2.29 & 2.36 & 2.43 & 2.50 & 2.57 \\
13 & 2.21 & 2.28 & 2.36 & 2.43 & 2.50 & 2.57 \\
14 & 2.21 & 2.28 & 2.35 & 2.42 & 2.50 & 2.57 \\
15 & 2.21 & 2.28 & 2.35 & 2.42 & 2.49 & 2.57 \\
16 & 2.20 & 2.28 & 2.35 & 2.42 & 2.49 & 2.56 \\
17 & 2.20 & 2.27 & 2.35 & 2.42 & 2.49 & 2.56 \\
18 & 2.20 & 2.27 & 2.34 & 2.42 & 2.49 & 2.56 \\
19 & 2.20 & 2.27 & 2.34 & 2.42 & 2.49 & 2.56 \\
20 & 2.20 & 2.27 & 2.34 & 2.42 & 2.49 & 2.56 \\
21 & 2.19 & 2.27 & 2.34 & 2.41 & 2.49 & 2.56 \\
23 & 2.19 & 2.27 & 2.34 & 2.41 & 2.49 & 2.56 \\
23 & 2.19 & 2.27 & 2.34 & 2.41 & 2.49 & 2.56 \\
24 & 2.19 & 2.26 & 2.34 & 2.41 & 2.49 & 2.56 \\
25 & 2.19 & 2.26 & 2.34 & 2.41 & 2.49 & 2.56 \\
26 & 2.19 & 2.26 & 2.34 & 2.41 & 2.48 & 2.56 \\
\hline & & & & & &
\end{tabular}

\section{Summary and conclusions}

Calorimetric measurements to determine the ability of PCM to store heat as a function of temperature are performed with a variety of methods and instruments. Some of them have been developed only in the last decade, especially to allow characterization of larger samples, even encapsulated PCM with volume in the order of $100 \mathrm{ml}$ and larger. In this paper, we gave an introduction, review, and recommendations for new reference materials for calibration and testing, needed to cover the full range of temperatures and sample sizes. Specifically, the calorimetric methods used for PCM were discussed, the different uses of reference materials, available certified reference materials, and their limitations when making measurements on PCM. The requirements on reference materials were discussed, specifically for calorimetric measurements on PCM, and some potential new reference materials were suggested in addition to those shown in Fig. 4.

For $T_{p c}$ and $\Delta_{p c} h$, water at $0{ }^{\circ} \mathrm{C}$ is useful as already measurements with the required uncertainty etc. are available. Another option are the n-alkanes, specifically dodecane $\mathrm{C} 12$ at about $-10^{\circ} \mathrm{C}$, tetradecane $\mathrm{C} 14$ at about $6^{\circ} \mathrm{C}$, hexadecane $\mathrm{C} 16$ at about $18^{\circ} \mathrm{C}$, and octadecane $\mathrm{C} 18$ at about $28^{\circ} \mathrm{C}$. These would cover the range from -10 to about $30^{\circ} \mathrm{C}$ well, especially when large sample masses are needed. Despite the fact that they are not certified reference materials, water, $\mathrm{C} 14$, and $\mathrm{C} 18$, where detailed information was found, are a big step forward compared to using materials and values just from some reference, with unknown purity, uncertainty, and information regarding how the values were determined from the measured data. However, specifically for $\mathrm{C} 12$ and $\mathrm{C} 16$ values with sufficiently low uncertainty are yet not available. While $\mathrm{C} 12$ would close the gap at low temperatures, several materials are needed to close the gap to indium (biphenyl might be a useful candidate), and especially beyond indium at higher temperatures. For $c_{p}$, water-salt mixtures, water-alcohol mixtures, as well as $\mathrm{n}$-alcanes in the liquid phase might be an option, each having specific advantages and disadvantages. In any case, for all options some more research seems to be needed. And especially for temperatures below $-10{ }^{\circ} \mathrm{C}$ and above $30^{\circ} \mathrm{C}$ other material classes like $\mathrm{n}$-alkanoles should also be investigated. They have not been considered in this first attempt here. At the end, a sufficient number of reference materials should be available to have the option to cover a temperature range of interest with at least 3 reference materials, one at the lower temperature end, one at the upper, and one somewhere in between. 


\section{Compliance with ethical standards}

Conflict of interest On behalf of all authors, the corresponding author states that there is no conflict of interest.

Open Access This article is licensed under a Creative Commons Attribution 4.0 International License, which permits use, sharing, adaptation, distribution and reproduction in any medium or format, as long as you give appropriate credit to the original author(s) and the source, provide a link to the Creative Commons licence, and indicate if changes were made. The images or other third party material in this article are included in the article's Creative Commons licence, unless indicated otherwise in a credit line to the material. If material is not included in the article's Creative Commons licence and your intended use is not permitted by statutory regulation or exceeds the permitted use, you will need to obtain permission directly from the copyright holder. To view a copy of this licence, visit http://creativecommons .org/licenses/by/4.0/.

\section{References}

1. Mehling H, Cabeza LF (2008) Heat and cold storage with PCM. Springer, Berlin

2. Rathgeber C, Schmit H, Miró L, Cabeza LF, Gutierrez A, Ushak SN, Hiebler S, Hauer A (2015) Analysis of supercooling of phase change materials with increased sample size - Comparison of measurements via DSC, T-History and at pilot plant scale. Proceeding of the $13^{\text {th }}$ International Conference on Energy Storage Greenstock

3. Debenedetti PG, Stanley HE (2003) Supercooled and glassy water. Phys Today 56(6):40-46

4. Della Gatta G, Richardson MJ, Sarge SM, Stølen S (2006) Standards, calibration, and guidelines in microcalorimetry - Part 2. Calibration standards for differential scanning calorimetry (IUPAC Technical Report). Pure Appl Chem 78(7):1455-1476. https://doi.org/10.1351/pac200678071455

5. Sabbah R, Xu-wu A, Chickos JS, Planas Leitão ML, Roux MV, Torres LA (1999) Reference materials for calorimetry and differential thermal analysis. Thermochim Acta 331:93-204

6. LGC: Analytical reference materials, standards and high purity solvents 2011/2012. Catalogue, 2010, p. 829-834, downloaded Feb. $21^{\text {st }} 2019$ from https://s3-eu-west-1.amazonaws.com/lgcst andards-assets/MediaGallery/PD/Analytical_reference_mater ials_standardsand_high_purity_solvents.pdf

7. Zhang Y, Jiang Y, Jiang Y (1999) A simple method, the T-history method, of determining the heat of fusion, specific heat and thermal conductivity of phase-changematerials. Meas Sci Technol 10:201-205

8. Marín JM, Zalba B, Cabeza LF, Mehling H (2003) Determination of enthalpy-temperature curves of Phase Change Materials with the T-history method - Improvement to temperature dependent properties. Meas Sci Technol 14:184-189

9. Lazaro A, Günther E, Mehling H, Hiebler S, Mariın JM, Zalba B (2006) Verification of a T-history installation to measure enthalpy versus temperature curves of phase change materials. Meas Sci Technol 17:2168-2174. https://doi. org/10.1088/0957-0233/17/8/016

10. Rathgeber $\mathrm{C}$, Schmit H, Hennemann P, Hiebler S (2014) Calibration of a T-History calorimeter to measure enthalpy curves of phase change materials in the temperature range from 40 to $200^{\circ} \mathrm{C}$. Meas Sci Technol 25:035011

11. Nernst W (1911) Der Energieinhalt fester Stoffe. Ann Phys 36:395-439
12. Archer DG, Kirklin DR (2000) NIST and standards for calorimetry. Thermochim Acta 347:21-30

13. Archer DG (2006) New NIST-traceable standards for calibration and validation of DSC. J Therm Anal Cal 85:131-134

14. Thoen J, Bloemen E, Van Dael W (1978) Heat capacity of the binary liquid system triethylamine-water near the critical solution point. J Chem Phys 68:735-744

15. Bloemen E, Thoen J, Van Dael W (1980) The specific heat anomaly in triethylamine-heavy water near the critical solution point. J Chem Phys 73:4628-4635

16. Thoen, J. Bloemen, E., Marijnissen, H. and Van Dael W.: Highresolution calorimetric investigation of phase transitions in liquids. Proceedings of the 8th Symposium on Thermophysical Properties, Nat. Bur. Stand., Maryland 1981, p. 422-427 (American Society of Mechanical Engineers, New York, 1982)

17. Thoen, J., Leys, J., Glorieux, C.: Adiabatic Scanning Calorimeter, European Patent EP 2591328 B1 (Sept. 02, 2015), US patent: US 9.310.263 B2 (April 12, 2016)

18. Leys J, Losada-Pérez P, Glorieux C, Thoen J (2014) Application of a novel type of adiabatic scanning calorimeter for high-resolution thermal data near the melting point of gallium. J Therm Anal Calorim 117:173-187. https://doi.org/10.1007/s1097 3-014-3654-1

19. Leys J, Losada-Pérez P, Slenders E, Glorieux C, Thoen J (2014) Investigation of the melting behavior of the reference materials biphenyl and phenyl salicylate by a new type adiabatic scanning calorimeter. Thermochim Acta 582:68-76

20. Leys J, Losada-Perez P, Glorieux C, Thoen J (2017) The melting behaviour of water and water-sodium chloride solutions studied by high-resolution Peltier-element-based adiabatic scanning calorimetry. J Therm Anal Calorim 129:1727-1739. https ://doi.org/10.1007/s10973-017-6330-4

21. Leys J, Glorieux C, Thoen J (2016) Temperature dependence of enthalpy and heat capacity of alkanes and related phase change materials (PCMs) with a Peltier-element-based adiabatic scanning calorimeter. MRS Adv 1:3935-3940. https://doi. org/10.1557/adv.2016.298

22. Paolini S, Mercuri F, Zammit U, Leys J, Glorieux C, Thoen J (2018) Analysis of rotator phase transitions in the linear alkanes hexacosane to triacosane by adiabatic scanning calorimetry and by photopyroelectric calorimetry. J Chem Phys 148:094503

23. Leys J, Duponchel B, Longuemart S, Glorieux C, Thoen J (2016) A new calorimetric technique for phase change materials and its application to alkane-based PCMs. Renew Sustain Energy Rev 5:4. https://doi.org/10.1007/s40243-016-0068-y

24. Kosny J, Kossecka E, Yarbrough D (2009) Use of a heat flow meter to determine active pcm content in an insulation. Proceedings of the 2009 International Thermal Conductivity Conference (ITCC) and the International Thermal Expansion Symposium (ITES), Pittsburgh, PA

25. Shukla N, Kosny J (2015) DHFMA method for dynamic thermal property measurement of PCM-integrated building materials. Curr Sustain Renew Energy Rep 2:41-46. https://doi. org/10.1007/s40518-015-0025-x

26. ASTM C1784-14, standard test method for using a heat flow meter apparatus for measuring thermal storage properties of phase change materials and products. ASTM International, West Conshohocken, PA, 2014, www.astm.org, DOI: https://doi. org/10.1520/C1784-14 (https://www.astm.org/Standards/C1784 .htm)

27. Göbel A, Vidi S, Klinker F, Hemberger F, Brütting M, Ebert H-P, Mehling $\mathrm{H}$ (2017) Method for the thermal characterization of PCM systems in the volume range from $100 \mathrm{ml}$ to $1000 \mathrm{ml}$. Int J Thermophys 38:67. https://doi.org/10.1007/s10765-017-2204-z 
28. Wan X, Fan J (2009) A new method for measuring the thermalregulatory properties of phase changematerial (PCM) fabrics. Meas Sci Technol 20:025110

29. Brütting $M$, Hemberger $F$, Vidi $S$, Wachtel J, Mehling $H$, Ebert HP (2016) Determination of heat capacity by means of longitudinal guarded comparative calorimeter correction methods. Int J Therm Sci 100:423-429

30. JCGM: Evaluation of measurement data - Guide to the expression of uncertainty in measurement. Joint Committee for Guides in Metrology, $1^{\text {st }}$ ed., September 2008

31. Gschwander S, Haussmann T, Hagelstein G, Sole A, Cabeza LF, Diarce G, Hohenauer W, Lager D, Ristic A, Rathgeber C, Hennemann P, Mehling H, Peñalosa C, Lazaro A (2015) Standardization of PCM characterization via DSC. Proceeding of the 13th International Conference on Energy Storage GREENSTOCK, Bejing

32. Himran S, Suwono A, Mansoori GA (1994) Characterization of alkanes and paraffin waxes for application as phase change energy storage medium. Energy Sources 16:117-128

33. Vidi S, Mehling H, Hemberger F, Haussmann T, Laube A (2014) Round robin test of paraffin phase change material. Int J Thermophys. https://doi.org/10.1007/s10765-014-1754-6

34. Osborne NS (1939) Heat of fusion of ice. A revision. J Res Natl Bur Stand 23:643-646. https://doi.org/10.6028/jres.023.043

35. S. Hiebler (2007) Kalorimetrische Methoden zur Bestimmung der Enthalpie von Latentwärmespeichermaterialien während des Phasenübergangs. Dissertation, Technische Universität München

36. Archer DG (2002) Enthapy of fusion of gallium. J Chem Eng Data 47:304-308

37. Hemminger WF, Cammenga $\mathrm{H}$ (1989) Methoden der Thermischen Analyse. Springer, Berlin

38. Dickinson HC, Harper DR 3rd, Osborne NS (1903) Latent heat of fusion of ice. Phys Rev 17:193

39. Dickinson HC, Osborne NS (1915) Specific heat and heat of fusion of ice. Bulletin of the Bureau of Standards, https://archi ve.org/details/speci1249811915248248dick/page/n3. Accessed 26 Mar 2019

40. Stefan Hiebler, Peter Hook, Henri Schmit: Unterkühlung in mikro-kompartierten organischen PCM (MIKOPUK) - Schlußbericht. Förderkennzeichen BMBF 03SF0435B. https://www.tib.eu/ de/suchen/id/TIBKAT:883208024/

41. Acree W, Chickos JS (2017) Phase transition enthalpy measurements of organic and organometallic compounds and ionic liquids sublimation vaporization and fusion enthalpies from 1880 to 2015. Part 2. C11-C192. J Phys Chem Ref Data 46(1):013104

42. NIST Chemistry WebBook: dodecane. https://webbook.nist.gov/ cgi/cbook.cgi?ID=C112403\&Units=SI\&Mask=4\#Thermo-Phase, Accessed 4 July 2019

43. NIST Chemistry WebBook: tetradecane. https://webbook.nist. gov/cgi/cbook.cgi?ID=C629594\&Units=SI\&Mask=4\#Therm o-Phase. Accessed 4 Nov 2019

44. Jan Leys, Christ Glorieux, Jan Thoen (2013) High-resolution adiabatic scanning calorimetry applied to the phase transitions in the $n$-alkanes tetradecane and tetracosane. Proceedings of the 31 st International Thermal Conductivity Conference and 19th International Thermal Expansion Symposium, June 26-30, 2011, Saguenay, Qc, Canada, Editors L. Kiss and L. St.-Georges, 57-66 (2013). ISBN 978-1-60595-055-6

45. NIST Chemistry WebBook: hexadecane. https://webbook.nist. gov/cgi/cbook.cgi?ID=C544763\&Units=SI\&Mask=4\#Therm o-Phase. Accessed 4 Nov 2019

46. NIST Chemistry WebBook: octadecane. https://webbook.nist. gov/cgi/cbook.cgi?ID=C593453\&Units=SI\&Mask=FFF. Accessed 4 Nov 2019

47. Archer DG, Carter RW (2000) Thermodynamic properties of the $\mathrm{NaCl}+\mathrm{H} 2 \mathrm{O}$ system. 4 heat capacities of $\mathrm{H} 2 \mathrm{O}$ and $\mathrm{NaCl}(\mathrm{aq})$ in cold-stable and supercooled states. J Phys Chem B 104(45):8563-8584

48. Engineering toolbox: ethylene glycol heat-transfer fluid. https ://www.engineeringtoolbox.com/ethylene-glycol-d_146.html, Accessed 6 Nov 2019

49. Vélez C, Khayet M, Ortiz de Zárate JM (2015) Temperaturedependent thermal properties of solid/liquid phase change even-numbered n-alkanes: $\mathrm{n}$-Hexadecane, $\mathrm{n}$-octadecane and n-eicosane. Appl Energy 143:383-394

50. Vélez C, Ortiz de Zárate JM, Khayet M (2015) Thermal properties of $n$-pentadecane, $n$-heptadecane and $n$-nonadecane in the solid/liquid phase change region. Int J Therm Sci 94:139-146

51. van Miltenburg JC (2000) Fitting the heat capacity of liquid n-alkanes: new measurements of n-heptadecane and n-octadecane. Thermochim Acta 343:57-62

Publisher's Note Springer Nature remains neutral with regard to jurisdictional claims in published maps and institutional affiliations. 